\title{
Drifter Studies in Warm Core Rings
}

\author{
by \\ Cynthia T. Tynan \\ Woods Hole Oceanographic Institution \\ Woods Hole, Massachusetts 02543 \\ and \\ Stanford B. Hooker \\ Rosensteil School of Marine and Atmospheric Science \\ University of Miami \\ Miami, Florida 33149
}

April 1984

Technical Report

Support for the preparation of this report and the purchase and processing of the data was provided by the National Science Foundation under grant OCE80-16983.

Reproduction in whole or in part is permitted for any purpose of the United States Government. This report should be cited as:

Woods Hole Oceanog. Inst. Tech. Rept. WHOI-84-27.

Approved for public release; distribution unlimited.

\section{Approved for Distribution:}

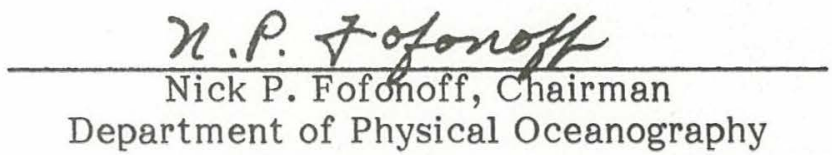




$$
-2-
$$

Table of Contents

Page

Abstract 3

Introduction

Discussion of drifters deployed during the following cruises:

$\begin{array}{ll}\frac{\text { Endeavor }}{\text { Endeavor }} 83 \\ \text { Endeavor } & 88 \\ \underline{\text { Endeavor }} 90 \\ \text { Bartlett } & 40-\mathrm{b}\end{array}$

Figure Captions

$10-11$

Table Captions

Tabulated dates of deployments and recoveries

Figures:

$$
\begin{aligned}
& \text { Configuration of drifters } \\
& \text { Plots of drifter trajectories }
\end{aligned}
$$

$16-17$

$18-31$

Tabulated positions of drifters

$32-50$

Year Day Calendar 


\begin{abstract}
The results of multiple deployments of surface drifters in warm core rings of the Gulf Stream are presented. Four satellite drifters (tracked by the Argos system) were deployed on nine separate occasions and two LORAN-C drifters (operated by the University of Miami) were deployed three times. Drifter studies were conducted during four cruises aboard the $R / V$ Endeavor in 1982 in conjunction with the Warm Core Rings Experiment and one cruise of the USNS Bartlett in January 1983 which was sponsored by the Office of Naval Research. Translational velocities and periods of rotation are provided for two rings: $82 \mathrm{~B}$ and $82 \mathrm{H}$.
\end{abstract}


Introduction

During 1982 four satellite tracked surface drifters and two LORAN-C drifters were deployed from the $\mathrm{R} / \mathrm{V}$ Endeavor in conjunction with the Warm Core Rings (WCR) Experiment. This program, which included four multi-ship cruises in 1982, was designed to study the physical, chemical, and biological processes of evolving, developed and senescent warm core rings of the Gulf Stream. Surface drifters provided estimates of ring center positions for three warm core rings: 82B, $82 \mathrm{H}$ and $82 \mathrm{I}$. Translational velocities and periods of rotation were also determined for rings $82 \mathrm{~B}$ and $82 \mathrm{H}$ (Table 1 ). The dates of deployment and recovery of the drifters are summarized in Tables $2 \mathrm{a}$ and $2 \mathrm{~b}$.

Positions of the satellite tracked drifters were established via the Argos system, Centre Spatial de Toulouse, France. Updated fixes, obtained on shore, were transmitted to the ships via telemail. Tables 3 - 11 contain the unsmoothed fixes for the Argos satellite drifters. Although several drifters continued to provide data after exiting a warm core ring, the listings are restricted to the time frame of the cruises. Occasionally when the drifters were in close proximity to the research vessel, the drifters could be tracked on radar due to their deployment configuration (Figures $1 \mathrm{a}$ and $1 \mathrm{~b}$ ). LORAN-C drifters, equipped to record positions internally, telemetered LORAN positions to the ship when proximity and atmospherics allowed.

Drifters were deployed within the rings as delineated by sea surface temperatures from satellite imagery and the depths of isotherms established by XBT surveys. The life histories of the buoys are discussed for the four 1982 WCR cruises aboard the R/V Endeavor and one cruise aboard the USNS Bartlett in 1983:



The satellite and LORAN-C buoys were constructed and deployed by the following investigators at the University of Miami: Robert Evans, Otis Brown, Kevin Leaman and Stan Hooker; and Marv Stalcup of the Woods Hole Oceanographic Institution. Figures $1 \mathrm{a}$ and $1 \mathrm{~b}$ illustrate the typical configuration of the LORAN-C and Argos satellite drifters deployed during the Warm Core Rings studies. 
Endeavor 83

Two LORAN-C drifter deployments were made during the first cruise in 1983: (1) a deployment in the central region of ring 82B during the first CTD transect; (2) a deployment in conjunction with the study of the high velocity frontal region. The first drifter, deployed on April 22 (year day 112) at 1515 GMT, consisted of a Woods Hole Oceanographic Institution (WHOI) radar reflecting buoy tethered to a Rosenstiel School of Marine and Atmospheric Science (RSMAS) LORAN-C buoy; a sediment trap of the Lamont-Doherty Geologica1 observatory, suspended $100 \mathrm{~m}$ beneath the radar reflecting buoy, served as a drogue. LORAN positions, which were recorded within the LORAN-C buoy, were telemetered to the ship twice an hour. The second LORAN-C drifter deployment, in the high velocity region, occurred on 29 April, day 119, at 1232 GMT. The LORAN buoy was tethered to a radar transponding, plank-on-edge buoy equipped with a window shade drogue at $100 \mathrm{~m}$.

To eliminate noise in the original data (Figure 2a), a cubic spline was fitted between points at 3 hour time intervals (Figure $2 \mathrm{~b}$ ). The noise may reflect changes in time delays due to varying meteorological conditions or shifts from ground waves to sky waves during the cruise. In Figure $2 b$ the smoothed track of the drifter within the ring is annotated at the arrows with the year day corresponding to 0 GMT. The drifter track for the high velocity region is similarly annotated with arrows at three hour intervals. The track of the drifter within the ring reflects the westward movement and anticyclonic circulation of ring 82B. A translational speed of $5.1 \mathrm{~km}^{-1}$ was $^{-1}$ determined from the positions on days 114 and 117 at 0 GMT. A rotational period of three days can be estimated for the ring. An azimuthal velocity of $1 \mathrm{~m} \mathrm{sec}^{-1}$ is computed from the eastward drift of the buoy deployed in the high velocity region.

Six days after deployment on April 28, day 118, the LORAN transmission from the ring center drifter had ceased due to low battery voltage; the drifter was recovered at 1024 GMT. The drifter in the high velocity region was recovered on day 120 at 1230 GMT after a 24 hour drift.

Endeavor 86

On June 14 at 1528 GMT during the first CTD survey of ring 82B, sate1lite drifter 02535 was deployed at CTD station 9, approximate ring center. 
The trajectory of the buoy confirmed the anticyclonic rotation and southwest translation of ring 82B. The buoy drifted from the center of the ring toward the higher velocity region as evidenced by the increased size of the cycloid (Figure 3). Ring 82B continued to exhibit a three day period of rotation. Between days 166 and 178 the ring translated $76.5 \mathrm{~km}$; this is equivalent to an average translational speed of $6.4 \mathrm{~km} \mathrm{day}^{-1}$, computed from the drifter positions at 0 GMT on days 166 and 178. A translational speed of $5.7 \mathrm{~km} \mathrm{day}^{-1}$ is obtained using estimates of ring center. The drifter was recovered by the $\mathrm{R} / \mathrm{V}$ Knorr on June 27 at 2200 GMT.

Although several LORAN-C drifter deployments were also made during Endeavor 86, they will not be presented here. The first drifter, number 7 , was deployed on June 14 at 1425 GMT. The track for this drifter was erratic and of questionable reliability. The other drifter, number 9, failed to provide useful data due to leakage.

\section{Endeavor 88}

Two satellite tracked drifters, 02535 and 03482, and one LORAN-C drifter were deployed on August 14 at 2110, 2150 and 2218 GMT respectively. The cycloidal tracks of all drifters reflect the anticyclonic circulation and continued southwest translation of ring $82 \mathrm{~B}$ (Figures $4 \mathrm{a}, 4 \mathrm{~b}$ and $4 \mathrm{c}$ ). The consistency in the transport of the three drifters is corroborated by their translations between year days 227 and 231: 96,91 and $92 \mathrm{~km}$. This corresponds to an average southwest translational velocity of approximately $23 \mathrm{~km} \mathrm{day}^{-1}$; a value of $18.5 \mathrm{~km} \mathrm{day}^{-1}$ is obtained using estimates of ring center. Ring $82 \mathrm{~B}$ was therefore translating at a higher speed than during April and June. Al1 drifters were recovered by the R/V Endeavor on August 19.

Buoy 02535 was redeployed in the estimated ring center at 1924 GMT on August 19. The drifter continued to drift anticyclonically between $36.5^{\circ} \mathrm{N}$ and $37^{\circ} \mathrm{N}$ for the next eighteen days. The ring had a three day period of rotation as evidenced by the three day cycle of the drifter (Figure 5). By September 7 (year day 250), the drifter had discontinued the anticyclonic rotation and was ejected from the ring. Although ring 82B persisted after this date (Robert Evans, personal communication), the drifter moved southward parallel to the coast. The drifter may have encountered the Gulf Stream on September 12 (year 
day 256). Following a five day excursion to the northwest, drifter 02535 again turned to the south and on day 263 became entrained by the Gulf Stream. For the next two weeks (September 19 - October 4) the buoy was transported in the Gulf Stream at a rate of $2 \mathrm{~m} \mathrm{sec}^{-1}$. On September 27 (year day 270) the drifter began to delineate the formation of two large meanders (Figure 6). This event fortuitously coincided with the fourth of the 1982 warm core ring cruises.

\section{Endeavor 90}

The focus of the fourth of the warm core rings cruises in 1982 was to study ring formation. The deployment and consequent east-southeast movement of satellite drifter 03481 (Figure 7), however, reflects the position of the Gulf Stream between year days 267 and 273. As drifter 03481 was recovered, drifter 02535 was completing its travel in a meander south of $39^{\circ} \mathrm{N}$ and beginning to delineate a northern meander/evolving ring. The latter became the focus of study. As drifter 02535 completed its path in the second meander, year day 277, the $\mathrm{R} / \mathrm{V}$ Endeavor conducted an XBT survey of the region. It is unclear from the drifter trajectory that the meander had closed and formed a distinct ring. The separation of ring $82 \mathrm{H}$ from the Gulf stream appeared to occur between days 277 and 283 as the drifter made a tight cyclonic revolution, of approximately $21 \mathrm{~km}$ radius, and then proceeded to the southwest (Figure 6). The buoy appears to have been caught in an associated cyclonic eddy adjacent to the evolving ring. Although the drifter stopped transmitting on October 10, year day 283, the depth of the 15 degree isotherm and the currents measured at $28 \mathrm{~m}$ via the shipboard APOC (Acoustic Profiling of Ocean Currents) system, corroborate that a large portion of the meander was independent from the Gulf Stream; the eastern most sector may have maintained some contact.

On October 5, year day 267, three satellite drifters were deployed to study the genesis and life history of ring $82 \mathrm{H}$ (Figure 8). The tracks of drifters 03482 and 03481 illustrate the anticyclonic circulation of ring $82 \mathrm{H}$; however, drifter 03480, which may be the best reflection of ring center, exhibited little cycloidal drift but was transported to the west-southwest (Figure 9). The translation of ring $82 \mathrm{H}$ from October $6-14$, computed from the track of 03480 , was $134 \mathrm{~km}$; the average translational speed was 
$16.8 \mathrm{~km} \mathrm{day}^{-1}$. A period of rotation of six days is estimated for the newly formed ring. Drifters 03481 and 03482 were not recovered; however, the R/V Knorr retrieved drifter 03480 on October 14 at 119 GMT.

Despite the proximity of the deployments of buoys 03481 and 03482 their paths eventually became quite different. By October 18, year day 291, ring $82 \mathrm{H}$ was interacting with a meander of the Gulf Stream. The interpretation of satellite imagery for October 18-19, provided by the National Weather Service (NWS)/National Earth Satellite Service and modified by the Atlantic Environmental Group (AEG), National Marine Fisheries Service (NMFS), shows ring 82H to be abutted to a Gulf Stream meander on the southwest and flanked by a streamer of shelf water to the east. Deformation of ring $82 \mathrm{H}$ was occurring during this time; the southward velocity of drifters 03481 and 03482 may reflect the Gulf Stream interaction, the currents associated with the streamer, or the outer high velocity region of the asymmetric ring (Figure 8). Ring $82 \mathrm{H}$ continued to persist and move to the southwest following the interaction with the Gulf Stream. Some surface signature of $82 \mathrm{H}$ appears in satellite imagery until February 7-8, 1983. The estimated position of the ring at that time was $39^{\circ} \mathrm{N} ; 72^{\circ} \mathrm{W}$.

Drifter 03481 continued its southward drift in association with a Gulf Stream meander; between year days 291 and 300 the drifter interacted with and passed through the Gulf Stream. The latter interpretation is based on two satellite images, October 18-19 and October 25-26, provided by NWS and modified by AEG. During this period, although the drifters were south of the Gulf Stream, their transport was parallel to the southern boundary of a closing meander. Neither drifter was incorporated in a cold core ring that was well defined by November 1, year day 303. Between days 309 and 324 (November 5 November 24) drifter 03481, now south of the Gulf Stream, looped anticyclonically, possibly in an eddy associated with another meander/developing cold core ring. By November 23 (year day 327) the drifter was incorporated in this ring (Figure 10). The cyclonic rotation was evident until the last transmission from the buoy, January 31 at 2322 GMT. With the exception of two very large rotations with periods of 6-7 days, the circulation period of the cold core ring was 3-4 days (Figure 11). 
Although all drifters were drogued at $100 \mathrm{~m}$, it is possible that the trajectories of drifters 03481 and 03482 may reflect drift due to wind. Since ring $82 \mathrm{H}$ continued to persist after its interaction with the Gulf Stream, it is unlikely that the movement of drifter 03482 reflects a dynamic mechanism for exchange between warm and cold core rings.

Drifter 03482 had a limited life in ring $82 \mathrm{H}$ and appeared to interact with the Gulf Stream after two anticyclonic rotations in ring $82 \mathrm{H}$ (Figure 12). Based on satellite imagery this drifter also crossed the Gulf Stream and moved eastward. By November 2 when a cold core ring $\left(65^{\circ} \mathrm{W} ; 36.5^{\circ} \mathrm{N}\right)$ had evolved, drifters 03482 and 03481 were well south of the Gulf Stream. It is possible that the drifter interacted with cold core rings which formed later in 1982. The drifter continued its eastward transport over the next year; a lapse in transmission occurred in 1983 after November 27, day 331. The final transmission obtained for drifter 03482 occurred on December 23, day 357. The position of the drifter at that time was $36.53^{\circ} \mathrm{N}$ and $38.46^{\circ} \mathrm{W}$.

Bartlett 40-b

On January 11, 1983 an Argos satellite drifter was deployed from the USNS Bartlett in conjunction with the study of winter cooling of a warm core ring. The drifter, launched at 0520 GMT in the estimated center of ring $82 \mathrm{I}$, attained an azimuthal velocity of $40 \mathrm{~cm} \mathrm{sec}^{-1}$ as it was transported to the southwest during the next four days (Figure 13). The short period of transmission is insufficient for determinations of circulation period and translational velocity. The final transmission from the buoy occurred on January 14 at 0929 GMT.

\section{Acknowledgements}

Programs used to smooth and plot the drifter data were developed by Roger Goldsmith. The personnel aboard the $\mathrm{R} / \mathrm{V}$ Endeavor were instrumental during drifter deployments and recoveries. The preparation of this report and the purchase and processing of the data was suppported by the National Science Foundation, grant OCE80-16983; Terrence Joyce and Raymond Schmitt, principa1 investigators. 


\section{Figure Captions}

Figure 1a: LORAN-C drifter configuration used during the Warm Core Rings Experiment.

Figure 1b: Satellite drifter configuration used during the Warm Core Rings Experiment.

Figure 2a: Unsmoothed tracks of LORAN-C surface drifters deployed during cruise 83 of the $\mathrm{R} / \mathrm{V}$ Endeavor. Deployments were made in the central and high velocity regions of warm core ring 82B on April 22 at 1515 GMT and April 29 at 1232 GMT respectively.

Figure 2b: The LORAN-C drifter tracks from Figure la smoothed with a cubic spline interpolation over three hour time intervals. Arrows on the track of the ring center drifter mark the beginning of each year day; arrows on the track of the drifter deployed in the high velocity region mark three hour time intervals.

Figure 3: Smoothed surface track of Argos satellite drifter 02535 deployed in the estimated center of ring $82 \mathrm{~B}$ on June 14 (year day 165) at 1528 GMT during cruise 86 of the R/V Endeavor. Arrows mark the positions at 0 GMT.

Figure 4a: Smoothed track of Argos satellite surface drifter 03482 deployed on August 14 (year day 226) at 2150 GMT in the estimated center of ring $82 \mathrm{~B}$ during cruise 88 of the R/V Endeavor. Arrows mark the positions at 0 GMT.

Figure 4b: Smoothed track of Argos satellite surface drifter 02535 deployed on August 14 (year day 226) at 2110 GMT in the estimated center of ring $82 \mathrm{~B}$ during cruise 88 of the $\mathrm{R} / \mathrm{V}$ Endeavor. Arrows mark the positions at 0 GMT.

Figure 4c: Track of LORAN-C surface drifter deployed on August 14 (year day 226 ) at 2218 GMT in the estimated center of ring 82B during cruise 88 of the R/V Endeavor. The track was smoothed with a cubic spline interpolation over three hour time intervals.

Figure 5: Partial track of satellite surface drifter 02535 deployed in the estimated center of ring $82 \mathrm{~B}$ on August 19 (year day 231) at 1924 GMT during cruise 88 of the R/V Endeavor. Arrows mark the positions of the drifter at the beginning of each year day.

Figure 6: Entire track of satellite surface drifter 2535 deployed during cruise 88 of the $R / V$ Endeavor. Track reflects the position of the Gulf Stream and the meanders/developing rings. Arrows, annotated with year days, mark the drifter positions at the beginning of each day (0 GMT). 
Figure 7: Track of Argos surface drifter 03481 deployed on September 24 (year day 267) at 2015 during cruise 90 of the R/V Endeavor. The track reflects the position of the Gulf Stream.

Figure 8: Tracks of three Argos surface drifters, 03480,03481, and 03482, deployed in ring $82 \mathrm{H}$ during cruise 90 of the $\mathrm{R} / \mathrm{V}$ Endeavor. Drifter 03480 is the best reflection of the ring center translation; drifters 03481 and 03482 reflect the anticyclonic rotation and westward movement of ring $82 \mathrm{H}$. The Gulf Stream (GS), warm core ring $(82 \mathrm{H})$ and shelf water intrusion ( $\mathrm{ShW}$ ) positions on year day 291 have been added to delineate the dynamic interactions occurring as drifters 03481 and 03482 move southward.

Figure 9: Track of Argos surface drifter 03480, deployed in the center of ring $82 \mathrm{H}$ on October 5 (year day 278) at 1525 GMT, during cruise 90 of the R/V Endeavor. Drifter 03480 provides the best estimate of ring center positions during this cruise.

Figure 10: Tracks of Argos surface drifters 03481 and 03482 deployed in ring $82 \mathrm{H}$ on October 5 (year day 278) during cruise 90 of the $R / V$ Endeavor. Arrows, some of which are annotated with the year day, mark the drifter position every three days a 0 GMT.

Figure 11: Entire track of Argos surface drifter 03481 deployed in ring $82 \mathrm{H}$ on October 5 (year day 278) at 1127 GMT. Arrows mark the position of the drifter every three days. The incorporation of the drifter in a cold core ring on day 321 is evident.

Figure 12: Track of Argos surface drifter 03481 in a cold core ring. Arrows mark the position of the drifter every 24 hours a 0 GMT; select arrows are annotated with the year day.

Figure 13: Entire track of Argos surface drifter 03482 in 1982 and 1983. Deployment occurred on October 5 (year day 278) at 2015 GMT. Arrows mark the positions of the drifter every seven days at 0 GMT; select arrows are annotated with the year day.

Figure 14: Track of Argos surface drifter 03480 deployed in ring $82 \mathrm{I}$ on 11 January 1983 at 0520 GMT from the USNS Bartlett. 
Table Captions

Table 1. Translational velocities and periods of rotation determined for two warm core rings from Argos and LORAN-C buoys.

Table 2a. Satellite drifter deployments in the Warm Core Rings Experiment 1982.

Table 2b. LORAN-C drifter deployments in the Warm Core Rings Experiment 1982.

Table 3. Positions of Argos satellite drifter 02535 during cruise 86 of the $\mathrm{R} / \mathrm{V}$ Endeavor.

Table 4. Positions of Argos satellite drifter 03482 during cruise 88 of the $\mathrm{R} / \mathrm{V}$ Endeavor.

Table 5. Positions of Argos satellite drifter 02535 during cruise 88 of the $\mathrm{R} / \mathrm{V}$ Endeavor.

Table 6. Positions, from the second deployment, of Argos satellite drifter 02535 during and after cruise 88 of the $\mathrm{R} / \mathrm{V}$ Endeavor.

Table 7. Positions of Argos satellite drifter 03481 during cruise 90 of the $\mathrm{R} / \mathrm{V}$ Endeavor.

Table 8. Positions of Argos satellite drifter 03480 during cruise 90 of the $\mathrm{R} / \mathrm{V}$ Endeavor.

Table 9. Positions of Argos satellite drifter 03481 during cruise 90 of the $\mathrm{R} / \mathrm{V}$ Endeavor.

Table 10. Positions of Argos satellite drifter 03482 during cruise 90 of the $\mathrm{R} / \mathrm{V}$ Endeavor.

Table 11. Positions of Argos satellite drifter 03480 during cruise 40-b of the USNS Bartlett.

Table 12. A Gregorian to year day calendar conversion. 
Table 1.

Translational velocities and periods of rotation determined for two warm core rings from Argos and LORAN-C buoys

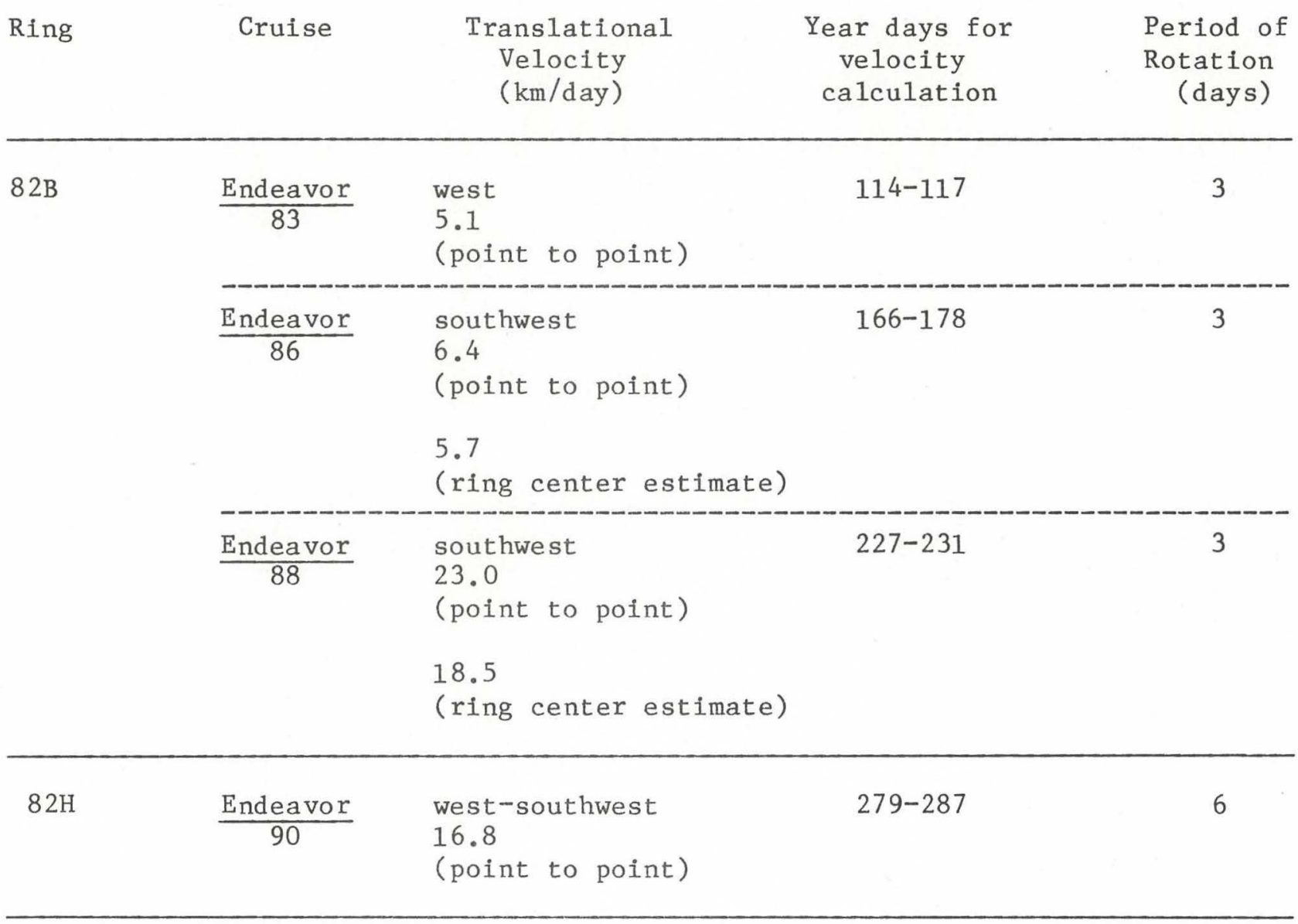


Table 2a.

S'atellite drifter deployments in the Warm Core Rings Experiment 1982

\begin{tabular}{|c|c|c|c|}
\hline \multirow[t]{2}{*}{ Cruise } & \multirow[t]{2}{*}{ Platform } & $\begin{array}{l}\text { Deployment } \\
\text { Year day GMT }\end{array}$ & \multirow{2}{*}{$\begin{array}{l}\text { Recovery } \\
\text { Year day GMT }\end{array}$} \\
\hline & & Year day GMT & \\
\hline$\frac{\text { Endeavor }}{\text { Ring } 82 B} 86$ & 02535 & $\begin{array}{l}165 \\
\text { June } 14,1928\end{array}$ & $\begin{array}{ll}178 & 2200 \\
\text { June } 27, & 1982 \text { (R/V Knorr) }\end{array}$ \\
\hline \multirow[t]{3}{*}{$\frac{\text { Endeavor }}{\text { Ring } 82 B} 88$} & 02535 & 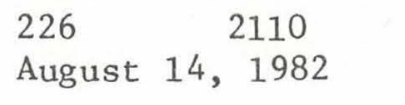 & $\begin{array}{lc}231 & 1730 \\
\text { August } & 19, \quad 1982\end{array}$ \\
\hline & 03482 & $\begin{array}{lc}226 & 2150 \\
\text { August } & 14,1982\end{array}$ & $\begin{array}{lc}231 & 1658 \\
\text { August } & 19,1982\end{array}$ \\
\hline & 02535 & 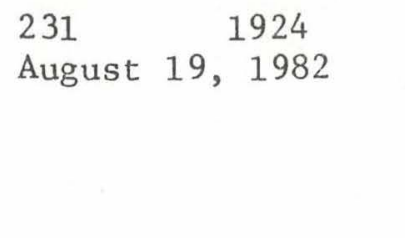 & $\begin{array}{l}283 \quad 2251 \\
\text { October } 10,1982 \\
\text { not recovered; stopped } \\
\text { transmitting during } \\
\text { Endeavor } 90\end{array}$ \\
\hline \multirow[t]{4}{*}{ Endeavor 90} & 03481 & $\begin{array}{ll}267 & 2015 \\
\text { September } & 24,1982\end{array}$ & $\begin{array}{ll}273 & 0954 \\
\text { September } & 30,1982\end{array}$ \\
\hline & 03481 & $\begin{array}{lc}278 & 1127 \\
\text { October } & 5,1982\end{array}$ & $\begin{array}{l}\text { not recovered; last } \\
\text { transmission on } \\
31 \quad 2322 \\
\text { January } 31,1983\end{array}$ \\
\hline & 03480 & $\begin{array}{lc}278 & 1545 \\
\text { October } & 5, \quad 1982\end{array}$ & $\begin{array}{l}287 \quad 1109 \\
\text { Octo ber } 14,1982 \text { (R/V Knorr) }\end{array}$ \\
\hline & 03482 & $\begin{array}{lc}278 & 2015 \\
\text { October 5, } & 1982\end{array}$ & $\begin{array}{l}\text { not recoverd; last } \\
\text { transmission on } \\
357 \quad 0719 \\
\text { December } \\
23,1983\end{array}$ \\
\hline USNS Bartlett & 03480 & 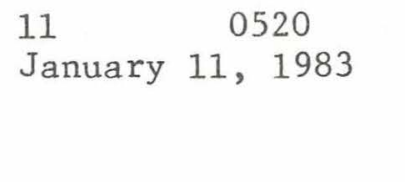 & $\begin{array}{l}\text { not recovered; last } \\
\text { transmission on } \\
\begin{array}{ll}13 & 2216 \\
\text { January } 13,1983\end{array}\end{array}$ \\
\hline
\end{tabular}


Table 2b.

LORAN-C Drifter Deployments in the Warm Core Rings Experiment 1982

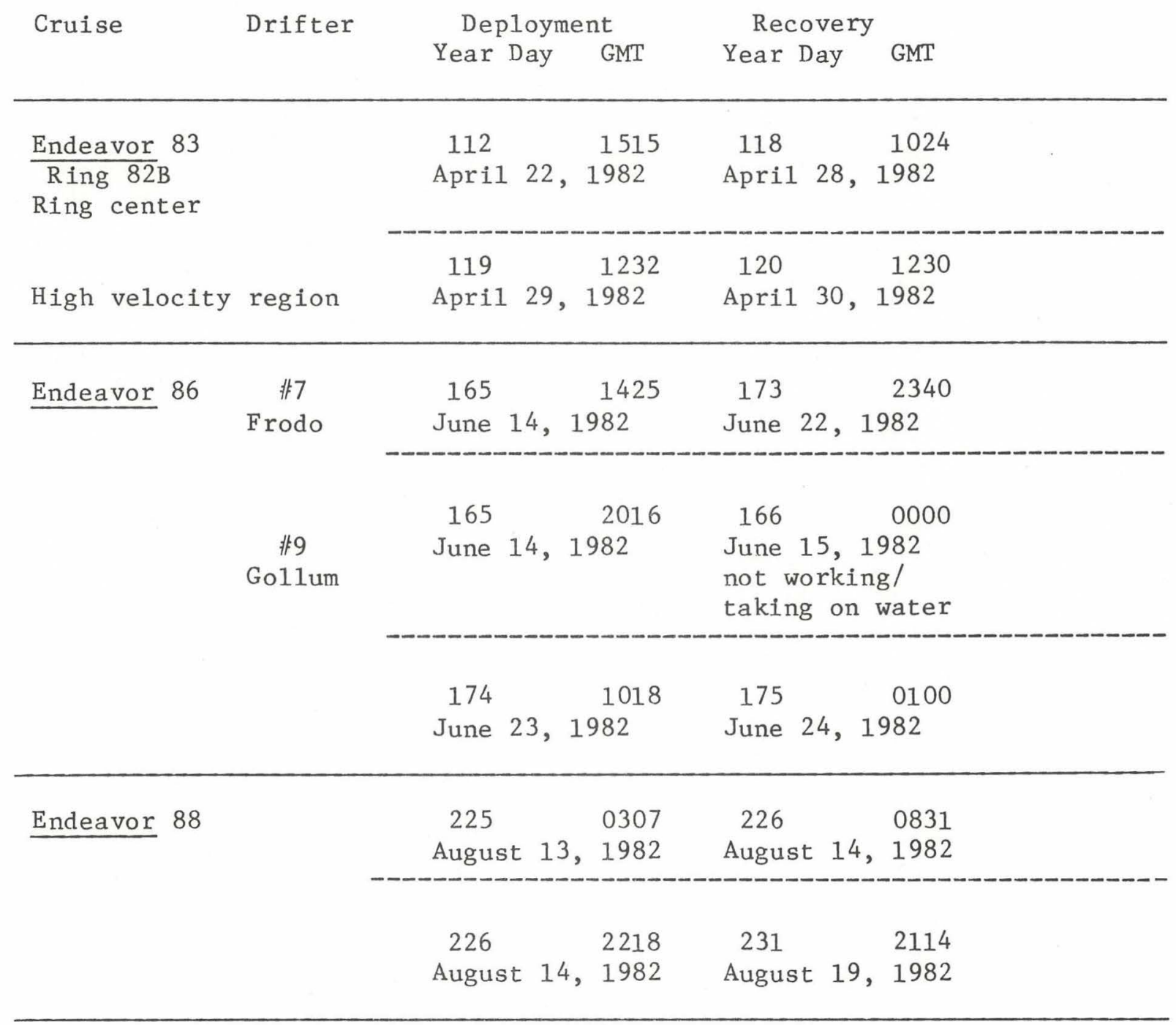




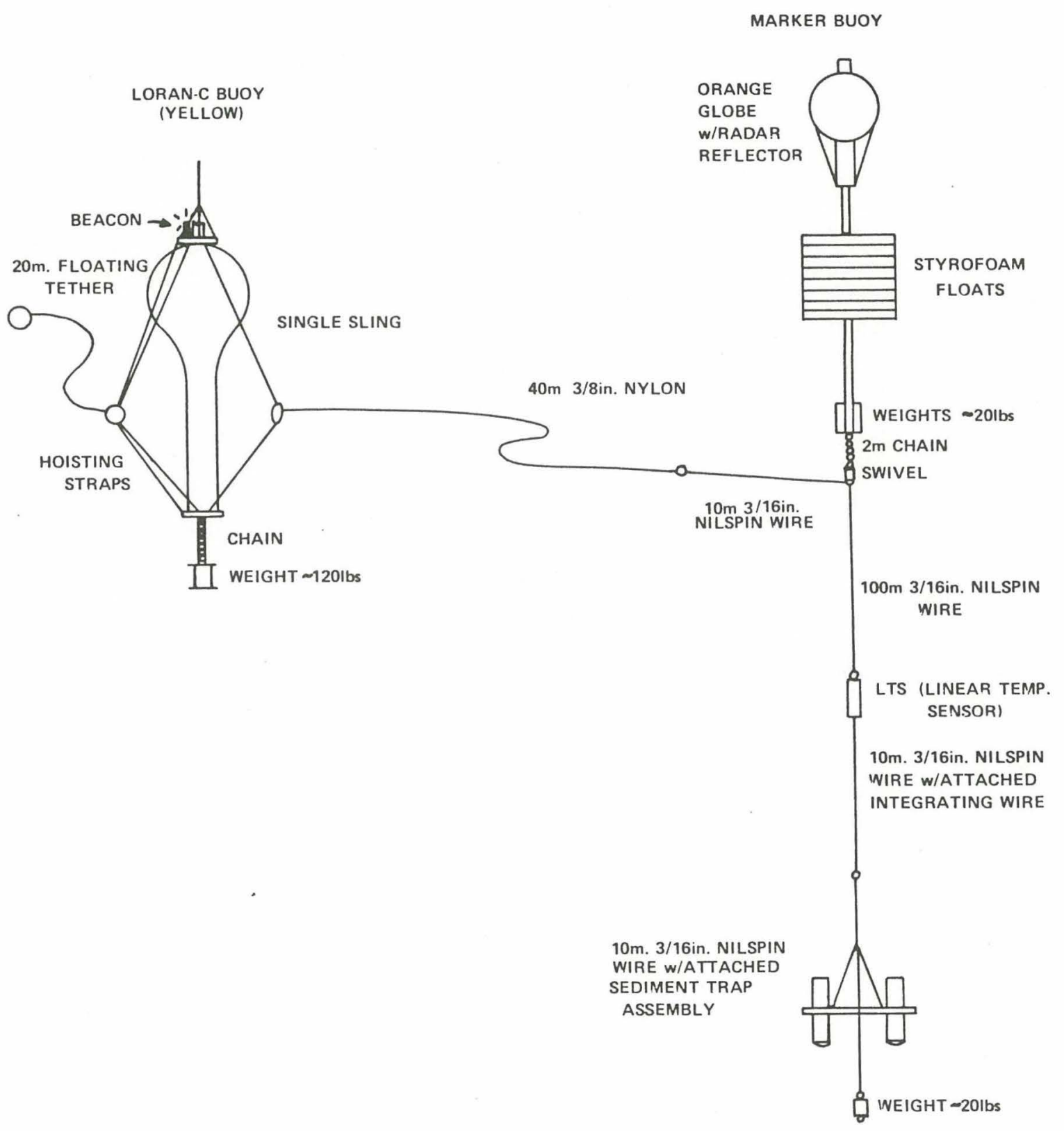

Figure 1a. LORAN-C drifter configuration used during the Warm Core Rings Experiment. 


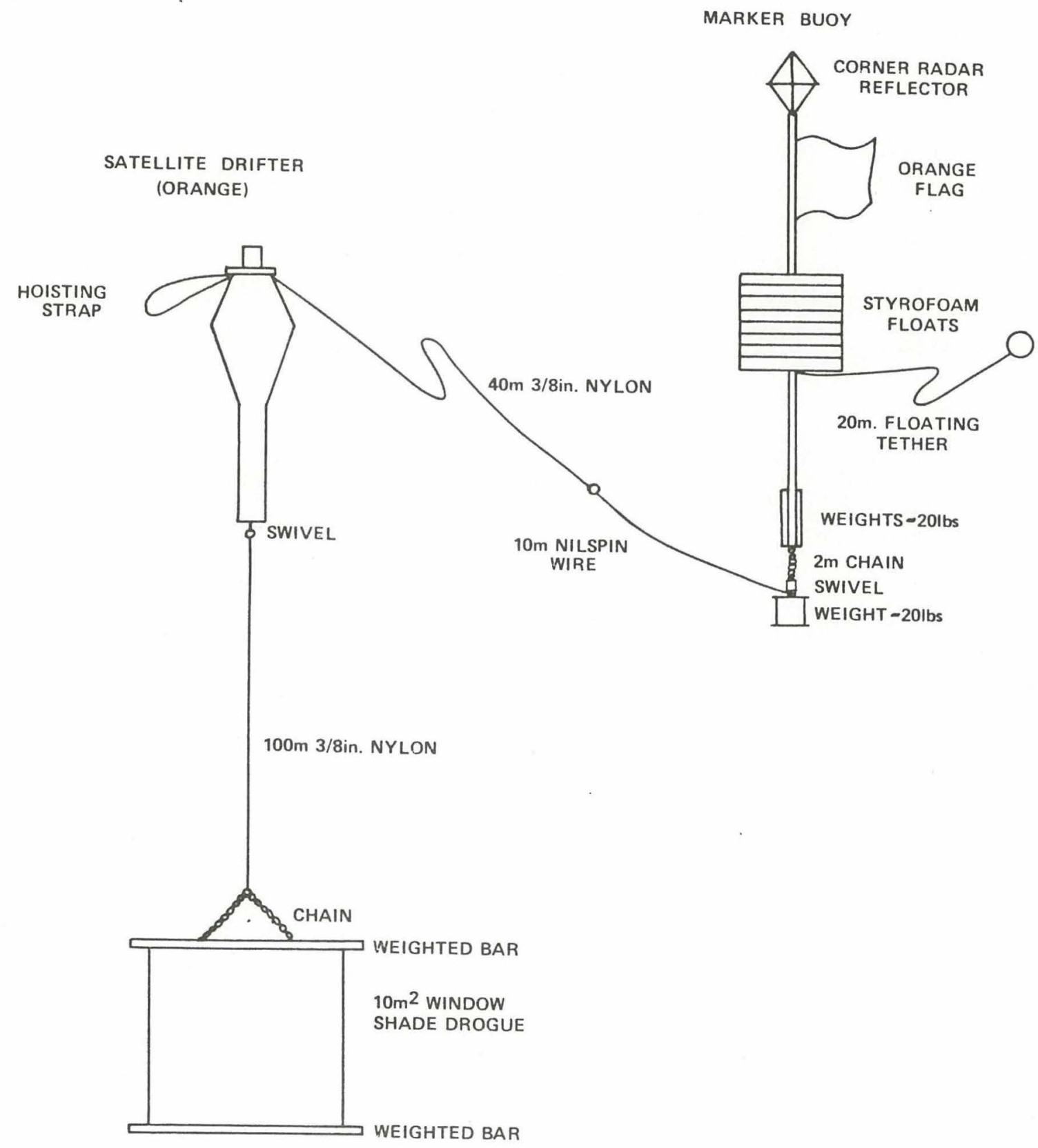

Figure 1b. Satellite drifter configuration used during the Warm Core Rings Experiment. 


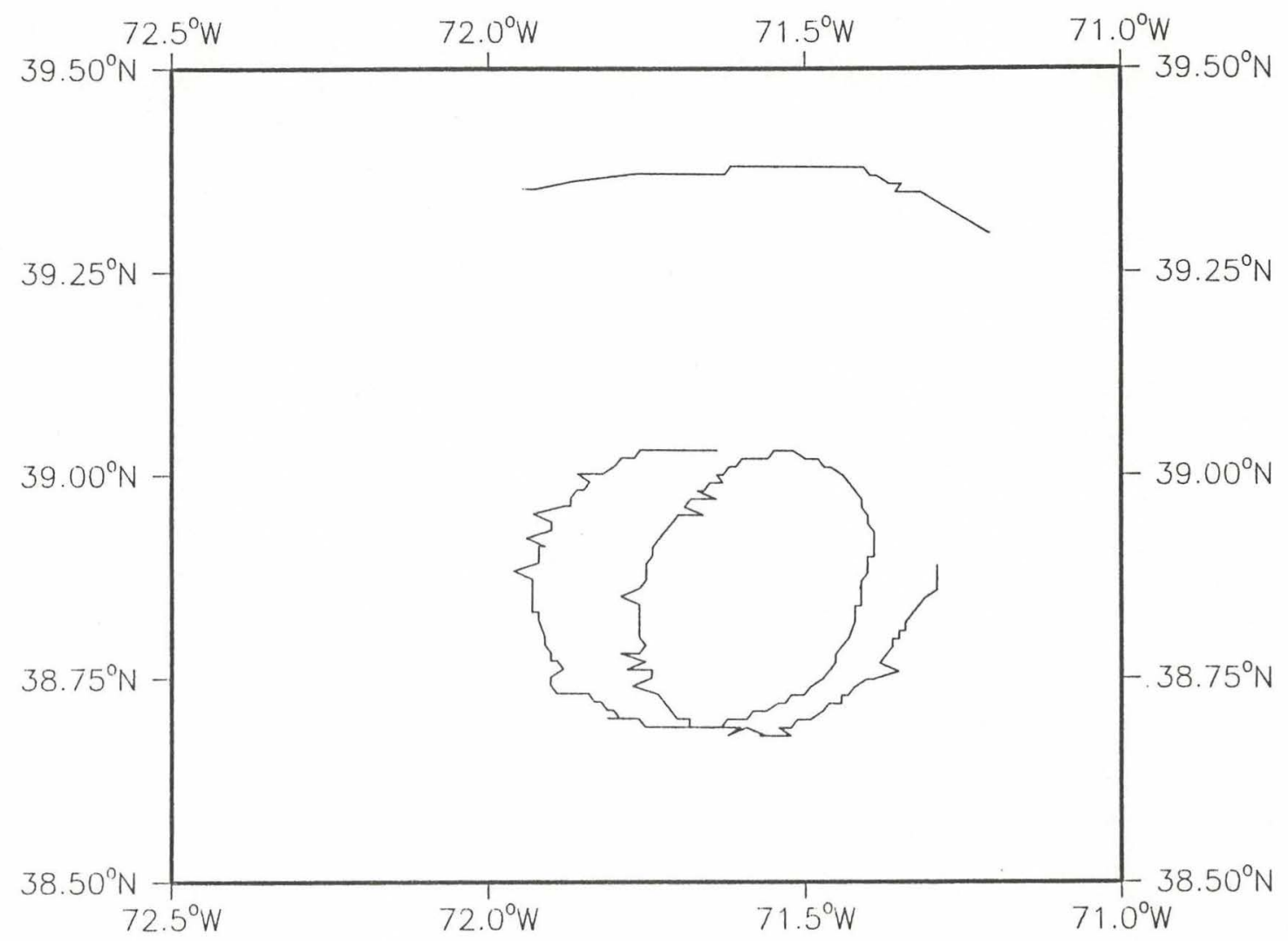

Figure 2a: Track of LORAN-C drifter deployed during Endeavor 83.

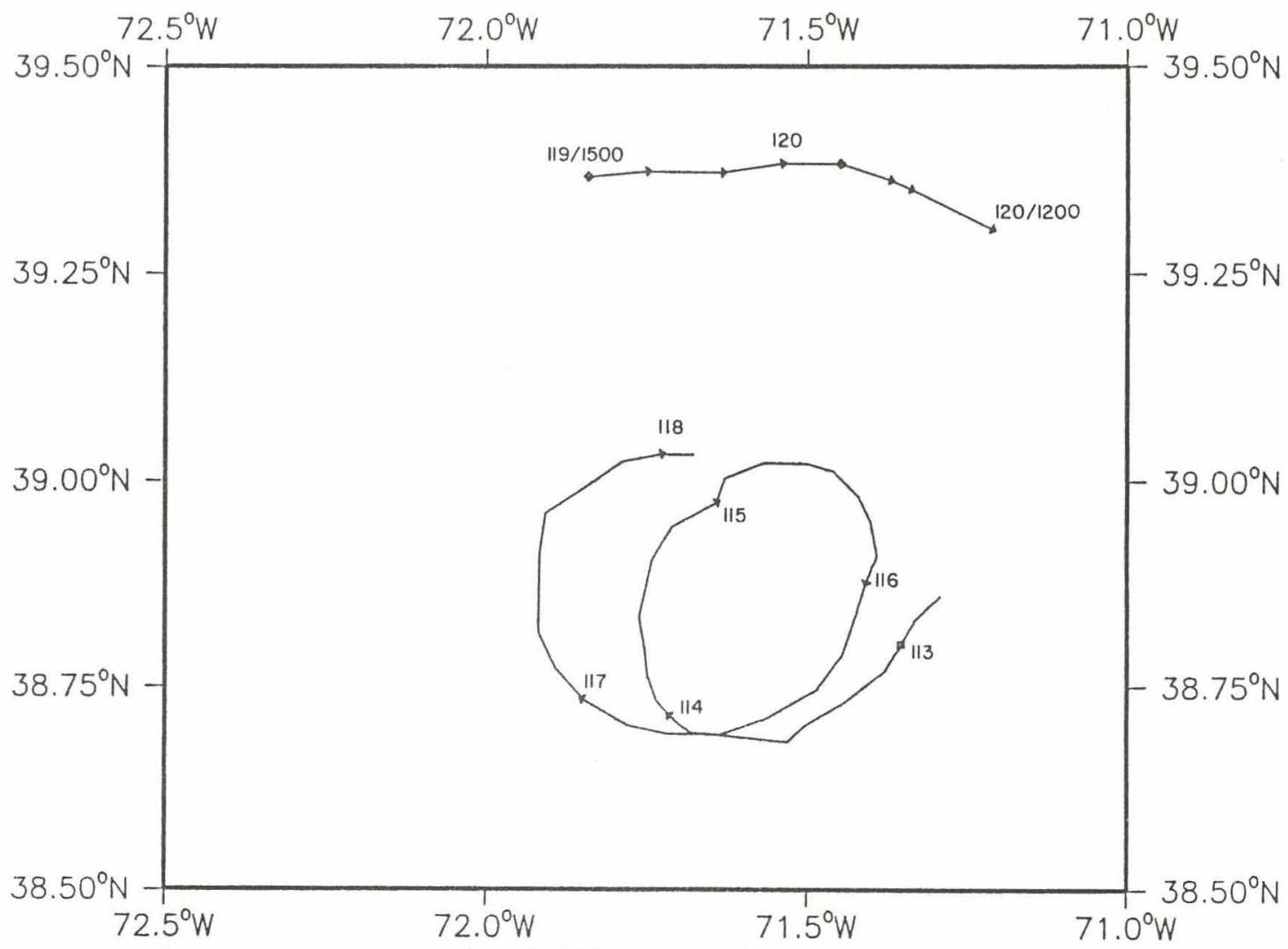

Figure 2b: Smoothed track of LORAN-C drifter deployed during Endeavor 83. 


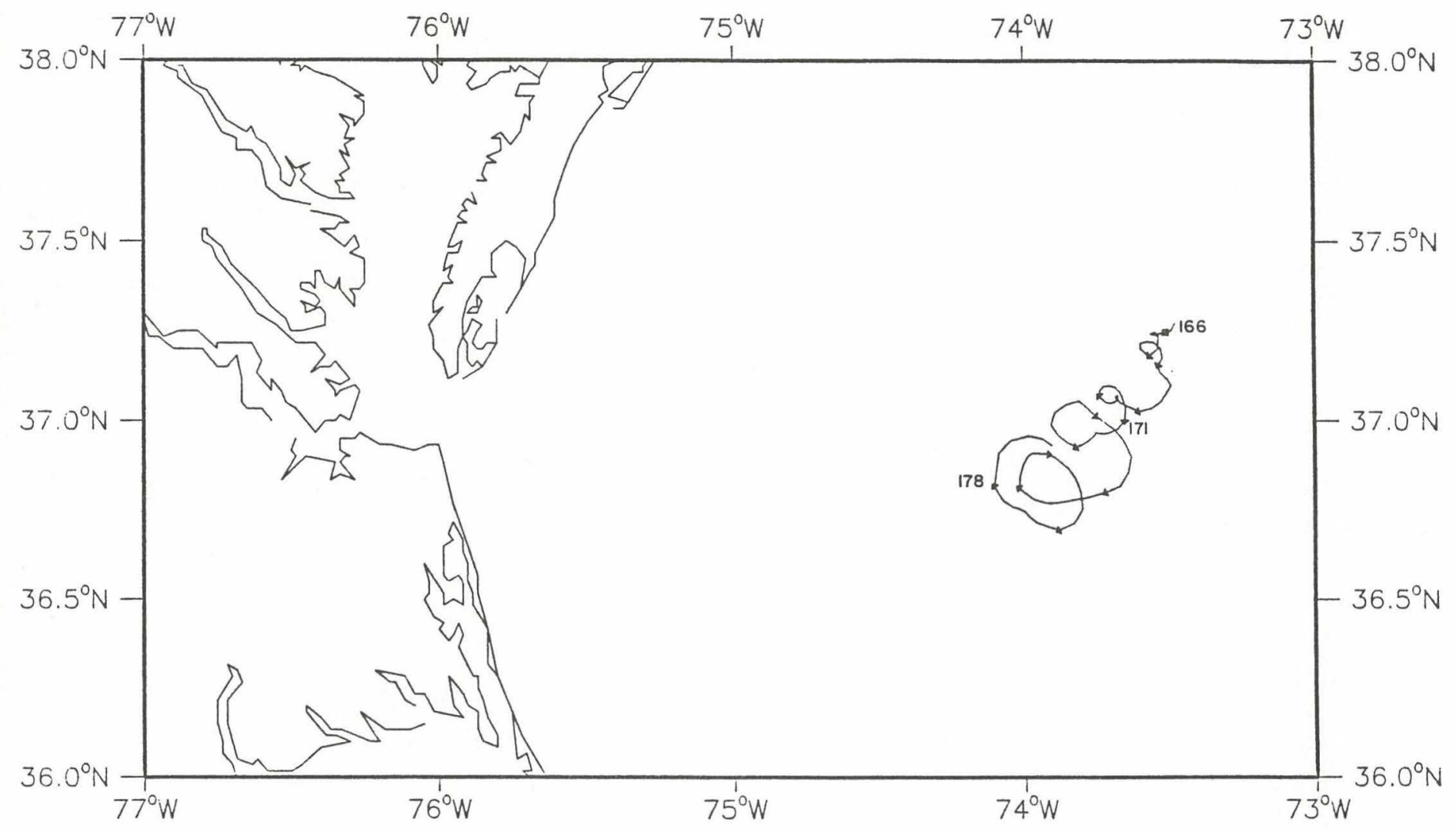

Figure 3: Smoothed surface track of Argos satellite drifter 02535 deployed in the estimated center of ring 82B on June 14 (year day 165) at 1528 GMT during cruise 86 of the R/V Endeavor. Arrows mark the positions at 0 GMT. 

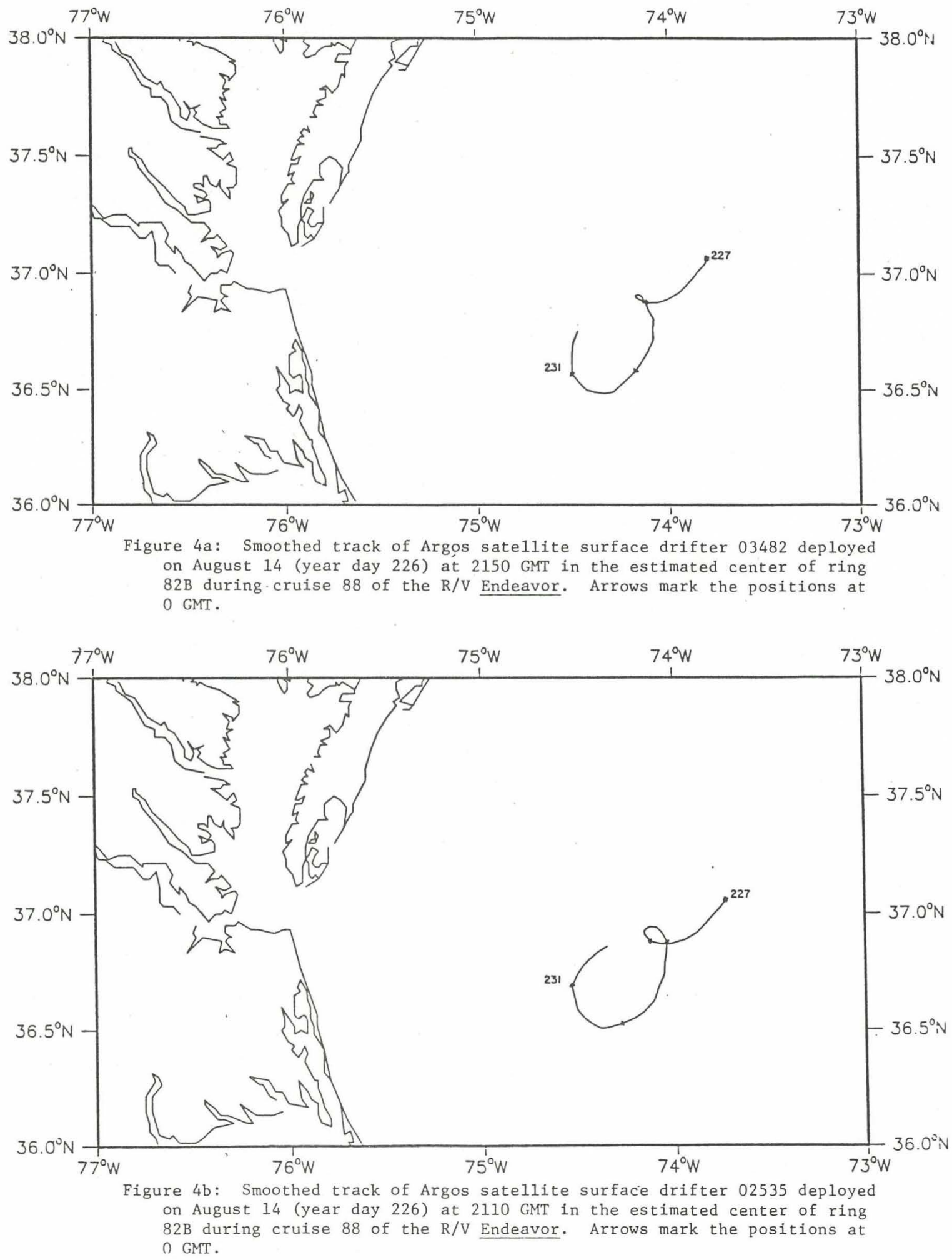


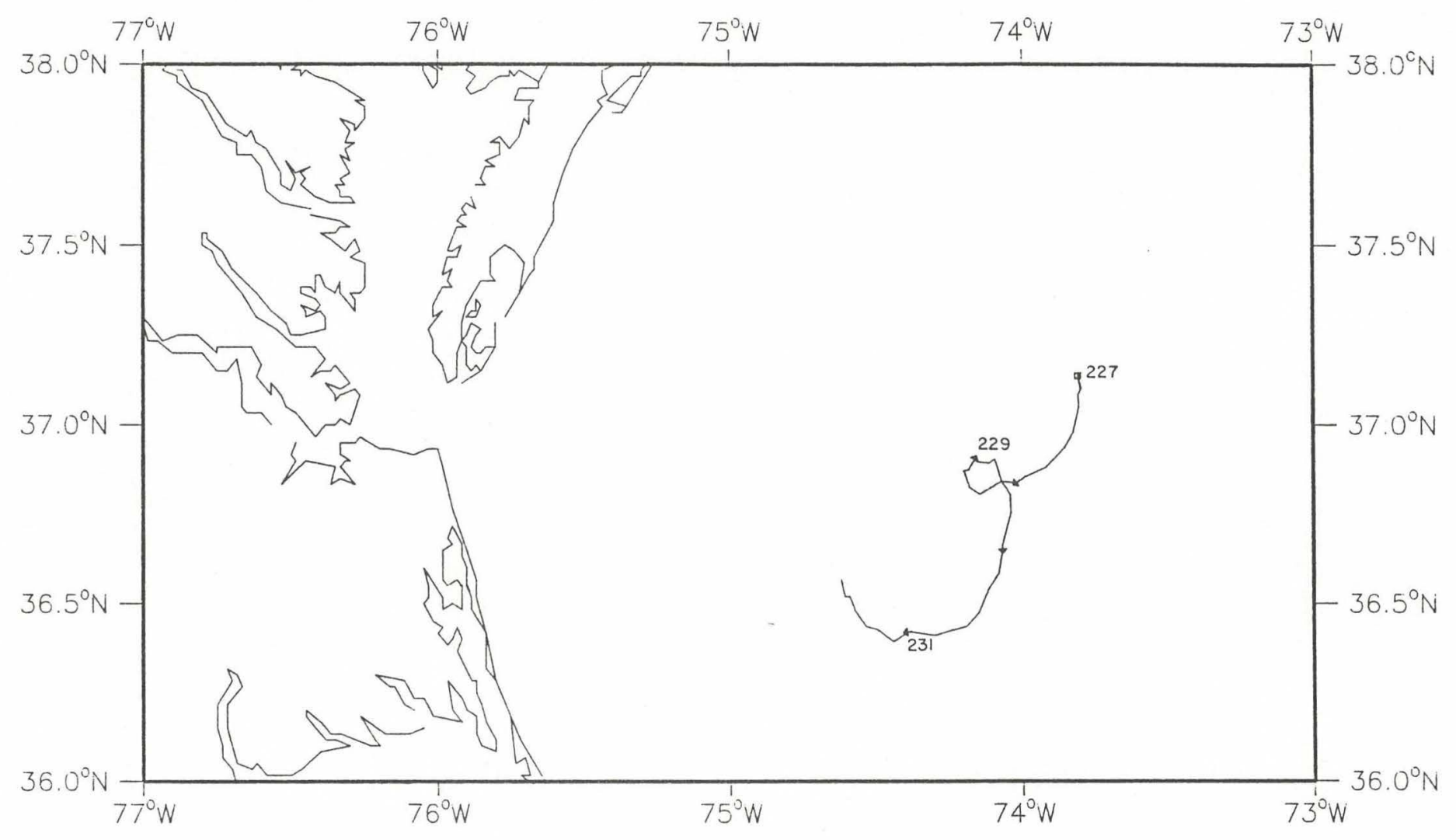

Figure 4c: Track of LORAN-C surface drifter deployed on August 14 (year day 226) at $2218 \mathrm{GMT}$ in the estimated center of ring $82 \mathrm{~B}$ during cruise 88 of the R/V Endeavor. 


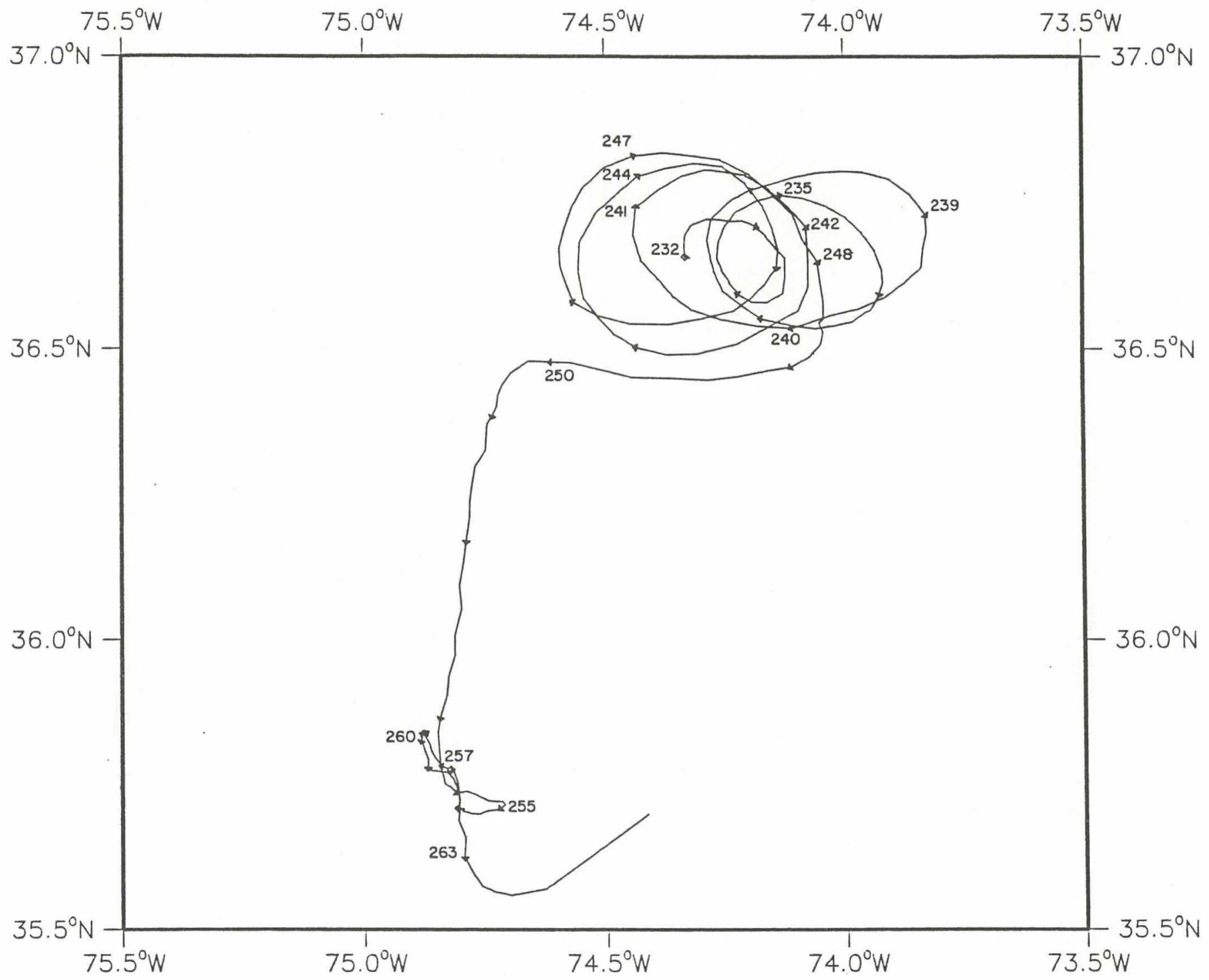

Figure 5: Partial track of satellite surface drifter 02535 deployed in the estimated center of ring $82 \mathrm{~B}$ on August 19 (year day 231) at 1924 GMT during cruise 88 of the R/V Endeavor. Arrows mark the positions of the drifter at the beginning of each year day. 


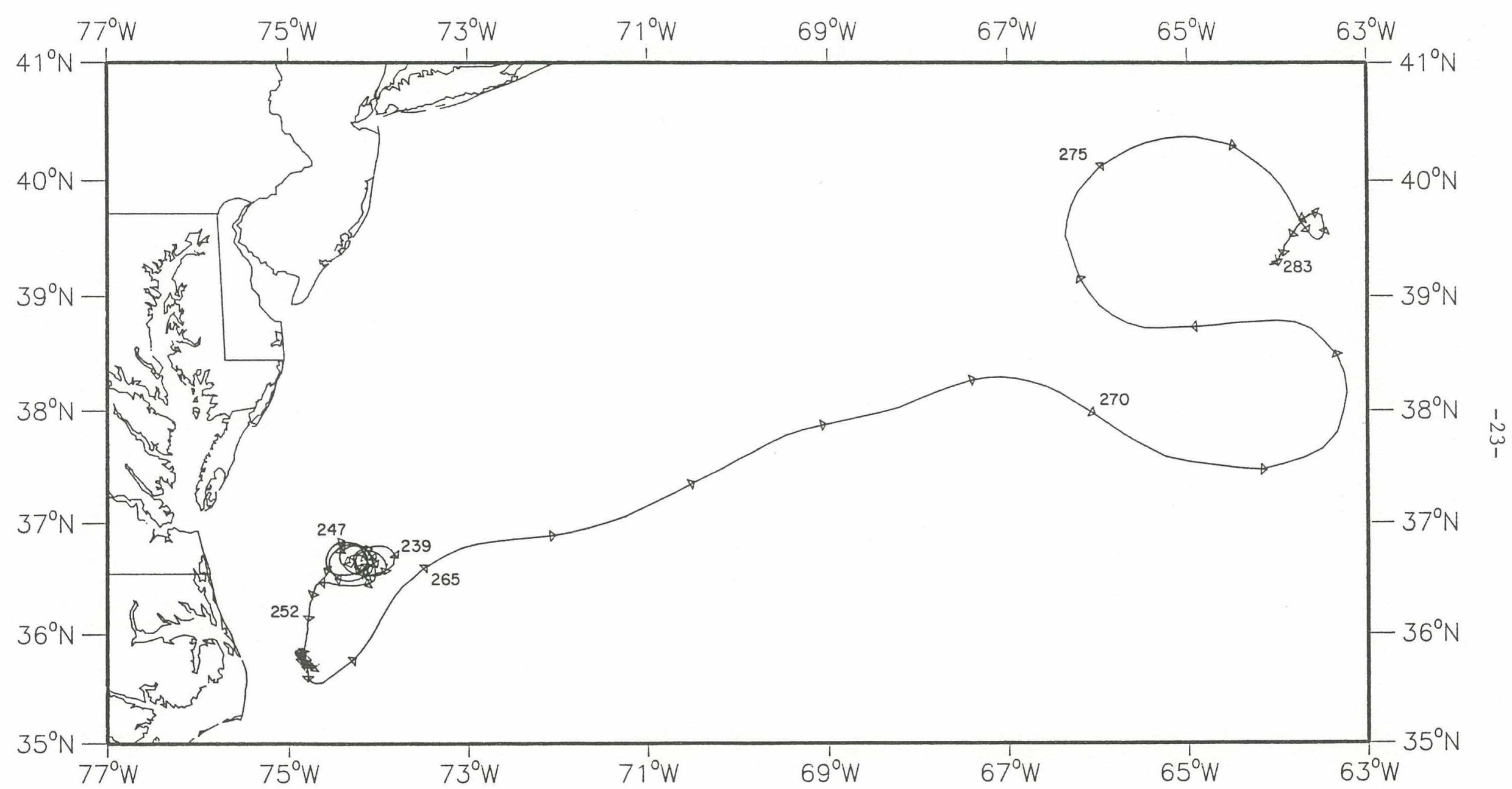

Figure 6: Entire track of satellite surface drifter 2535 deployed during cruise 88 of the R/V Endeavor. Track reflects the position of the Gulf Stream and the meanders/developing rings. Arrows, annotated with year days, mark the drifter positions at the beginning of each day (0 GMT). 


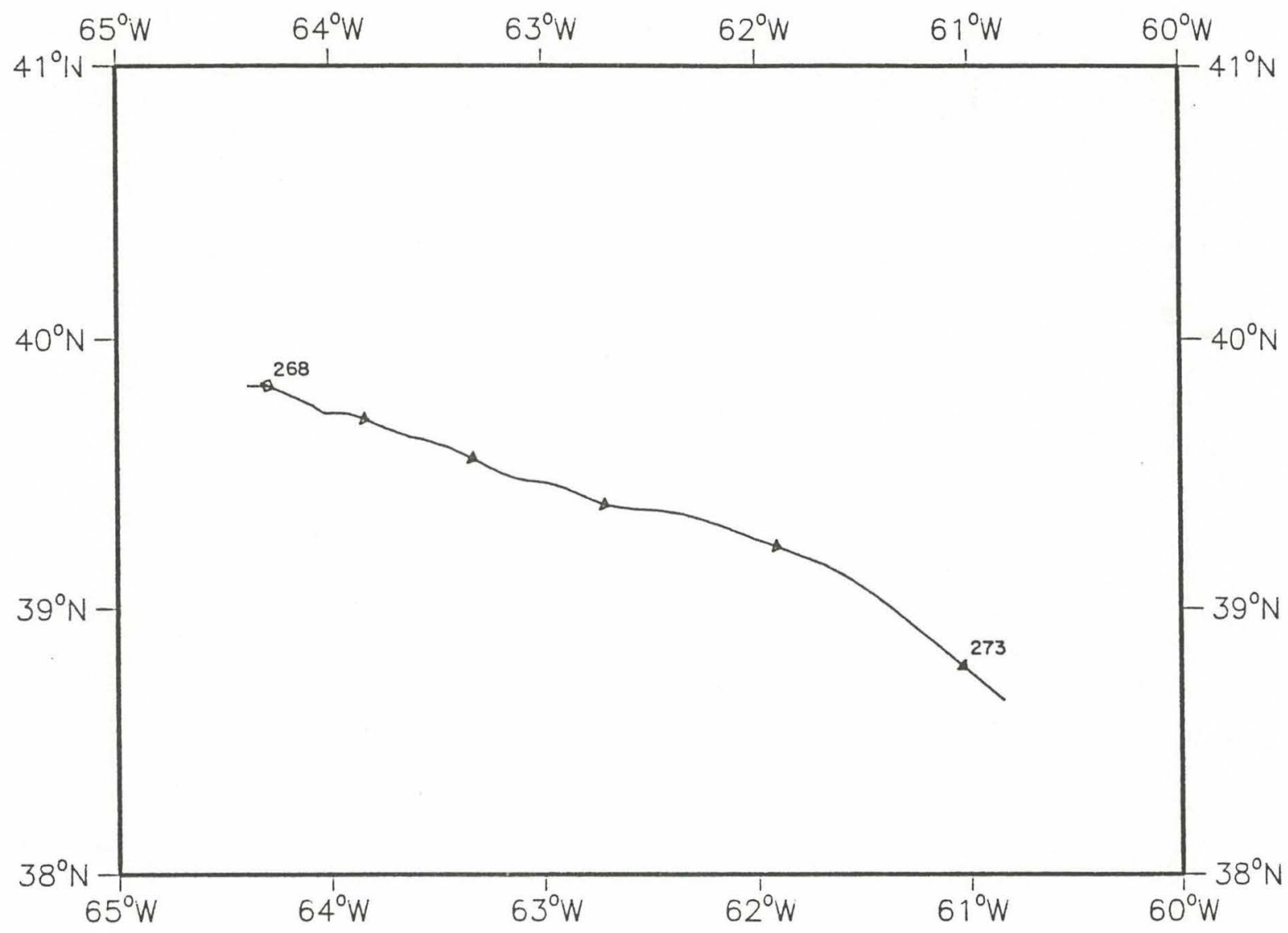

Figure 7: Track of Argos surface drifter 03481 deployed on September 24 (year day 267) at 2015 during cruise 90 of the R/V Endeavor.

The track reflects the position of the Gulf Stream. 


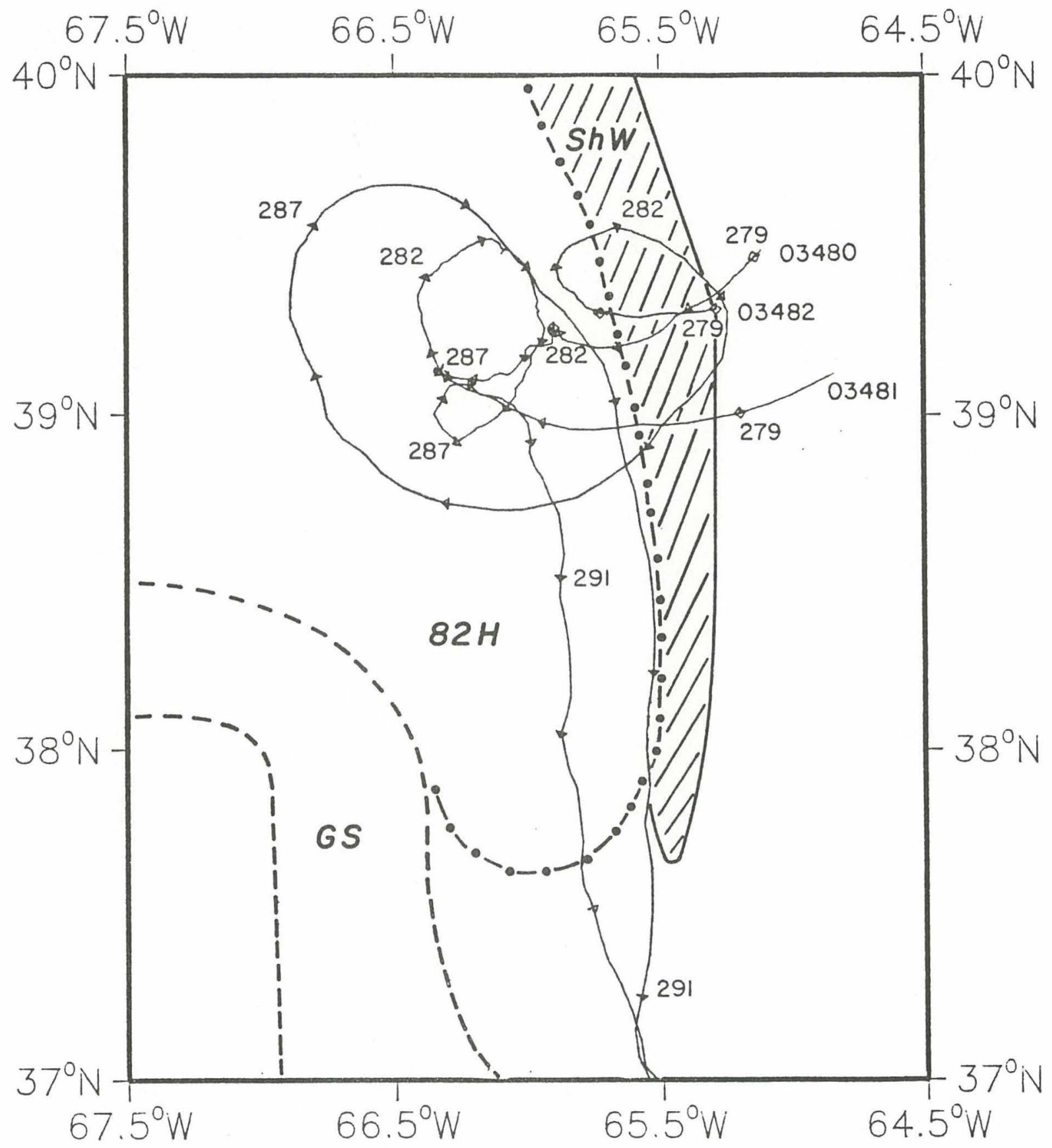

Figure 8: Tracks of three Argos surface drifters, 03480, 03481, and 03482 , deployed in ring $82 \mathrm{H}$ during cruise 90 of the $\mathrm{R} / \mathrm{V}$ Endeavor. Drifter 03480 is the best reflection of the ring center translation; drifters 03481 and 03482 reflect the anticyclonic rotation and westward movement of ring $82 \mathrm{H}$. The Gulf Stream (GS), warm core ring $(82 \mathrm{H})$ and shelf water intrusion (ShW) positions on year day 291 have been added to delineate the dynamic interactions occurring as drifters 03481 and 03482 move southward. 


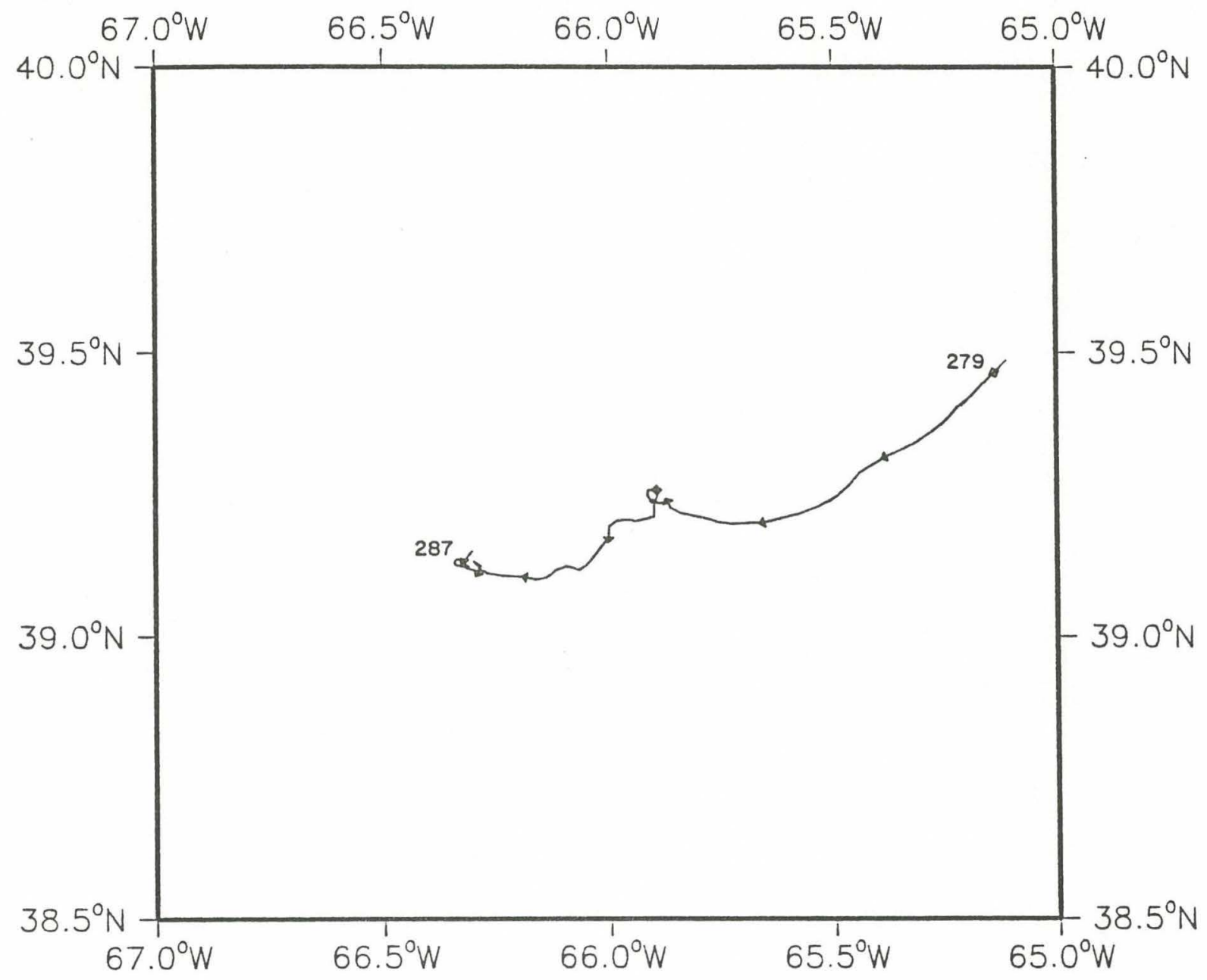

Figure 9: Track of Argos surface drifter 03480, deployed in the center of ring $82 \mathrm{H}$ on October 5 (year day 278) at 1525 GMT, during cruise 90 of the $\mathrm{R} / \mathrm{V}$ Endeavor. Drifter 03480 provides the best estimate of ring center positions during this cruise. 


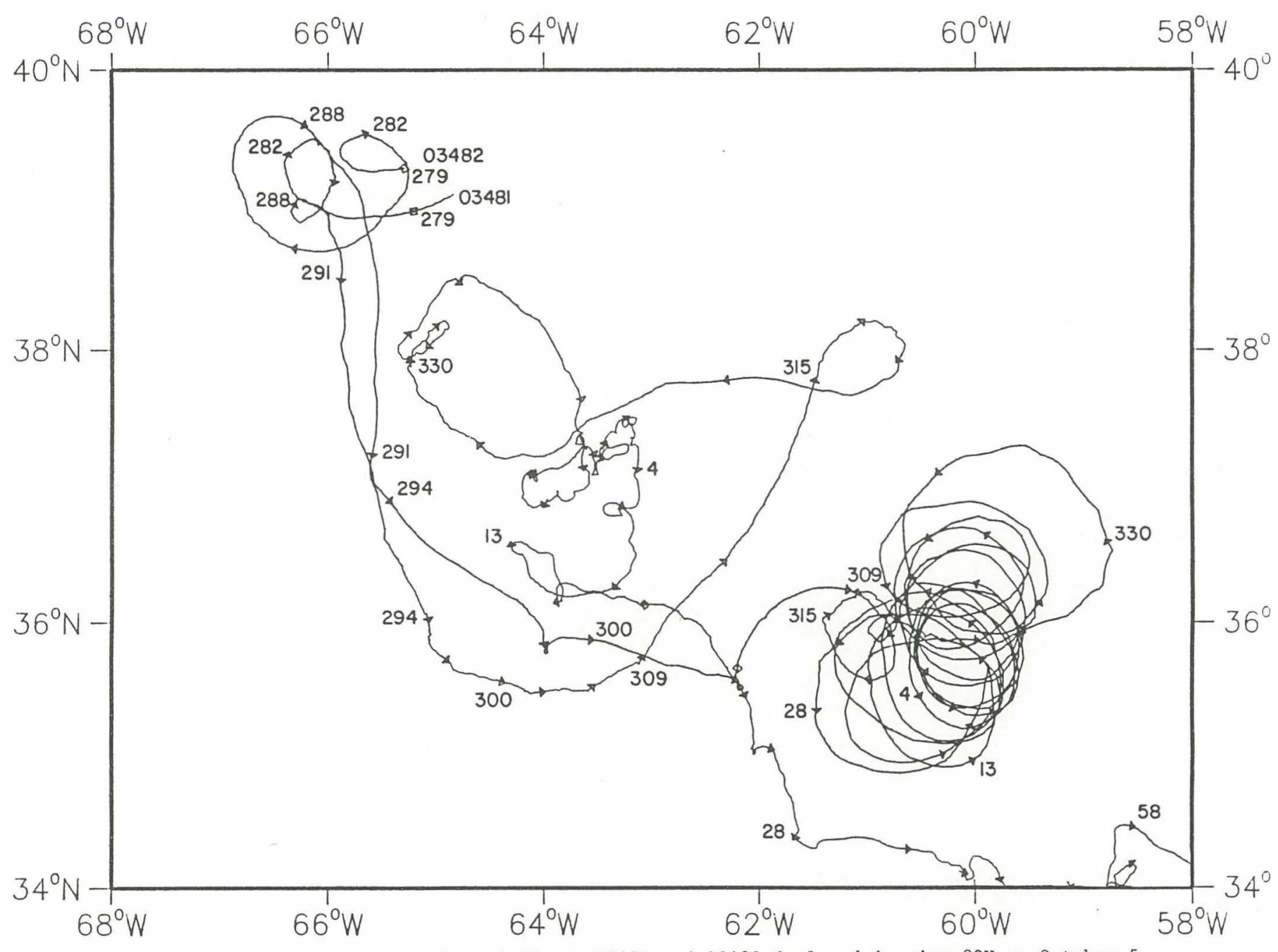

Figure 10: Tracks of Argos surface drifters 03481 and 03482 deployed in ring 82H on October (year day 278) during cruise 90 of the $R / V$ Endeavor. Arrows, some of which are annotated with the year day, mark the drifter position every three days at 0 GMT. 




Figure 11: Entire track of Argos surface drifter 03481 deployed in ring $82 \mathrm{H}$ on October 5 (year day 278) at 1127 GMT. Arrows mark the position of the drifter every three days. The incorporation of the drifter in a cold core ring on day 321 is evident. 


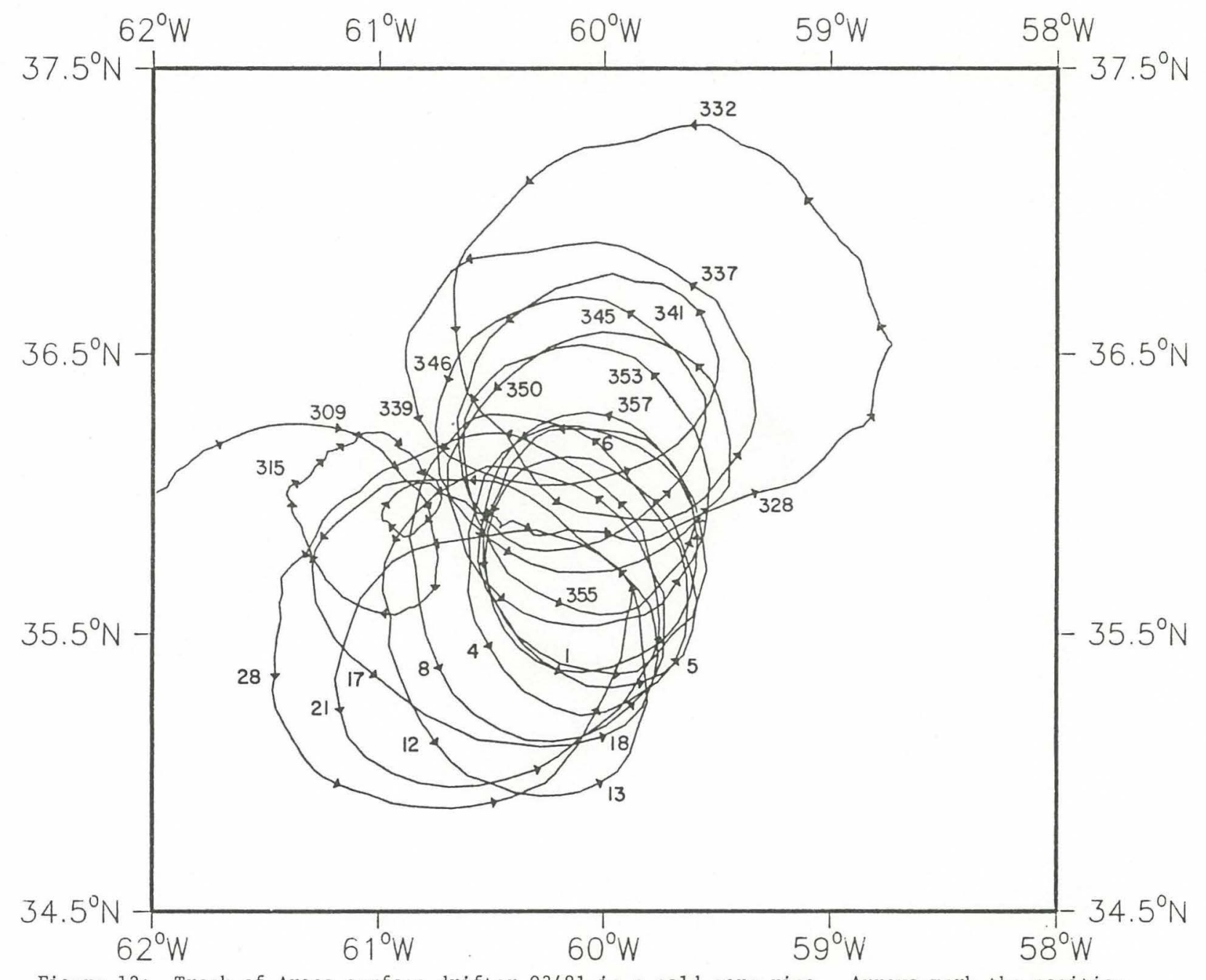

Figure 12: Track of Argos surface drifter 03481 in a cold core ring. Arrows mark the position of the drifter every 24 hours at 0 GMT; select arrows are annotated with the year day. 


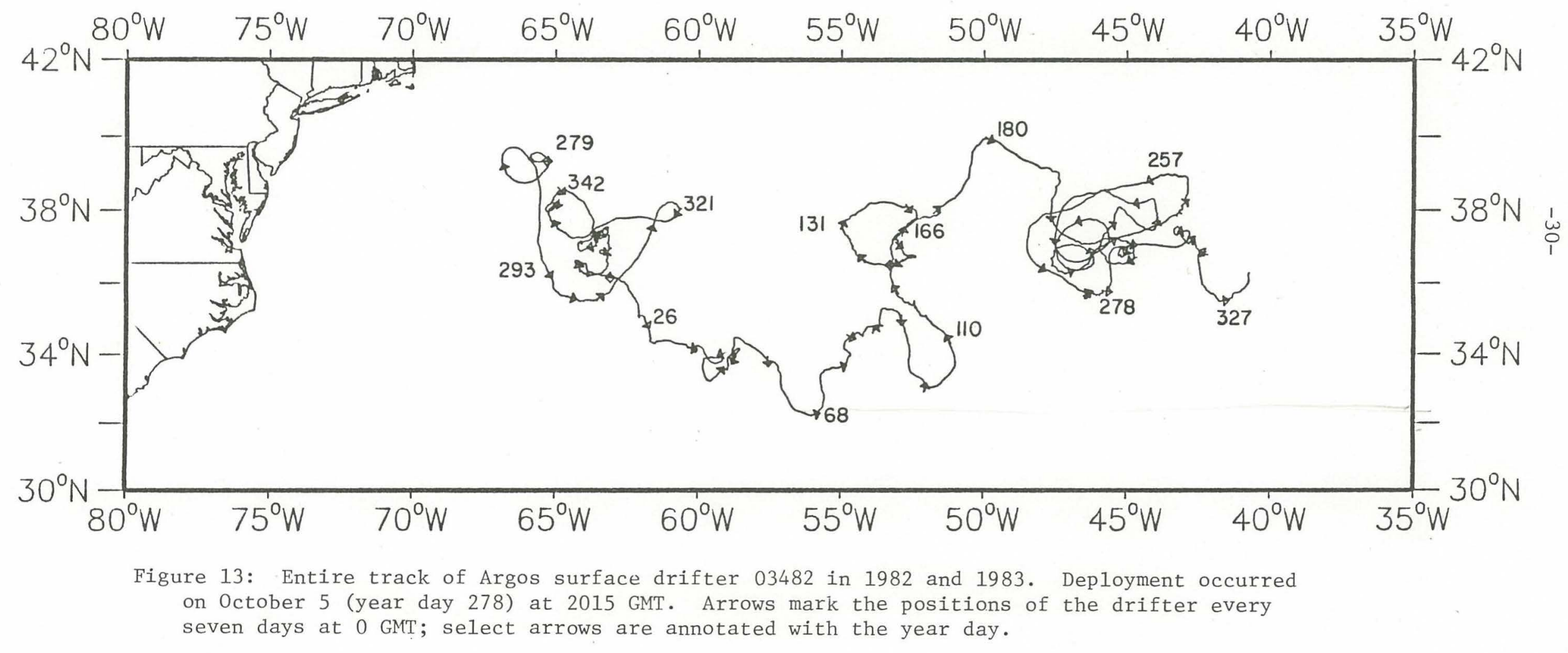




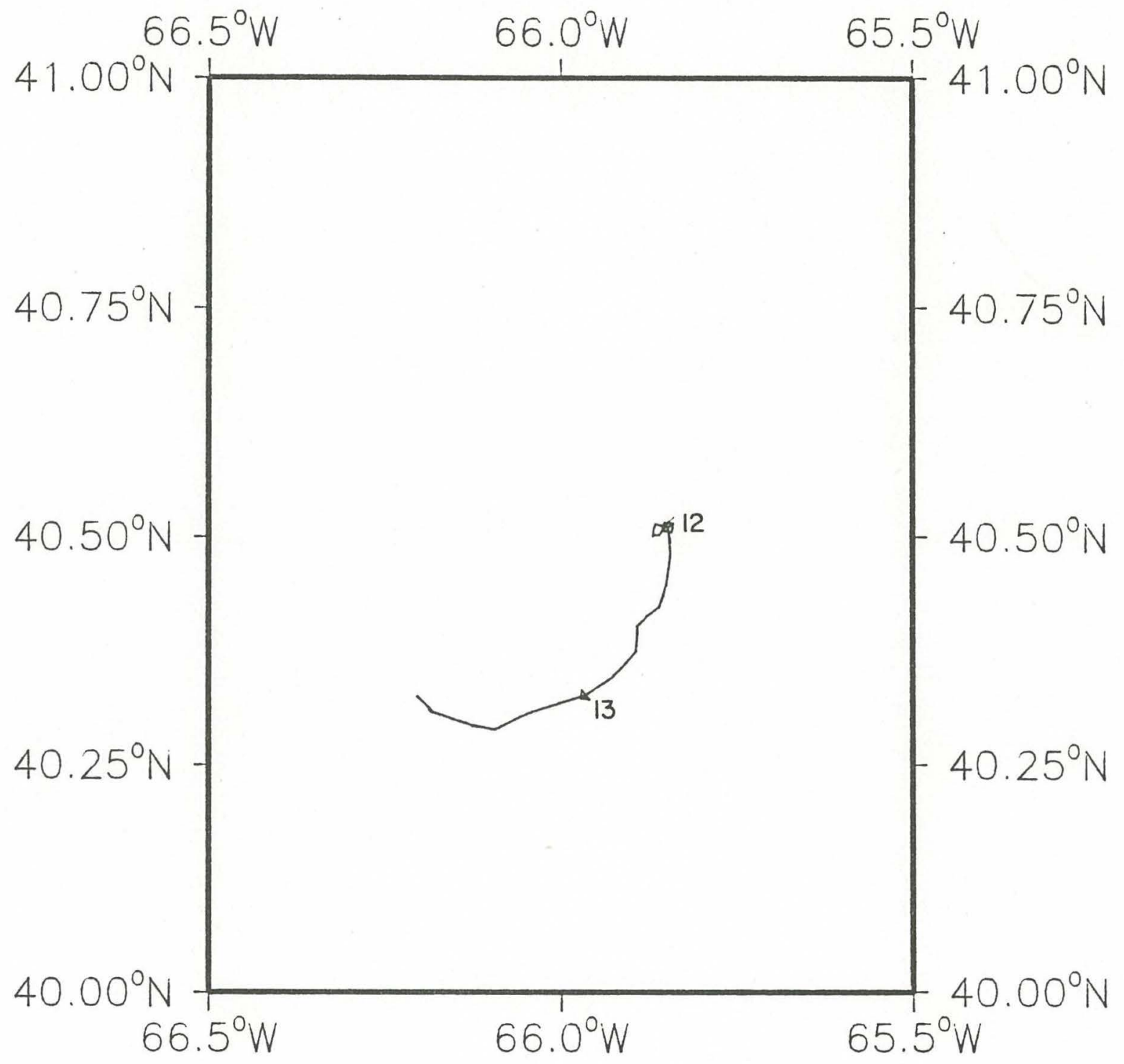

Figure 14: Track of Argos surface drifter 03480 deployed in ring 82I on 11 January 1983 at 0520 GMT from the USNS Bartlett. 
Table 3.

Positions of Argos drifter 02535 Endeavor 86 SHIP: ENDEAVOR CRUISE: 86 DATES: JUNE $10-30,1982$
DRIFTER: 2535

\begin{tabular}{|c|c|c|c|c|}
\hline E & TIME & $Y E A R$ & DAY & LATITUDE \\
\hline 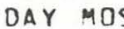 & GMT & & & $D F G$ \\
\hline
\end{tabular}

\begin{tabular}{|c|c|c|c|c|}
\hline 14 & 1710 & 165 & 37.277 & -73.469 \\
\hline 14 & 1857 & 165 & 37.263 & -73.484 \\
\hline 14 & 2037 & 165 & 37.250 & -73.487 \\
\hline 6 & 2221 & 165 & 37.248 & -73.496 \\
\hline 15 & 0714 & 166 & 37.238 & -73.554 \\
\hline 5 & 0901 & 166 & 37.242 & -73.560 \\
\hline 15 & 1217 & 166 & 37.248 & -73.543 \\
\hline 5 & 1404 & 166 & 37.239 & -73.531 \\
\hline 6 & 1839 & 166 & 37.214 & -73.535 \\
\hline 5 & 2025 & 166 & 37.205 & -73.529 \\
\hline 5 & 2337 & 166 & 37.182 & -73.559 \\
\hline 16 & 0122 & 167 & 37.181 & -73.567 \\
\hline 6 & 0702 & 167 & 37.204 & -73.600 \\
\hline 6 & 0849 & 167 & 37.216 & -73.596 \\
\hline 16 & 1154 & 167 & 37.221 & -73.572 \\
\hline 16 & 1341 & 167 & 37.224 & -73.556 \\
\hline 16 & 1827 & 167 & 37.197 & -73.522 \\
\hline 16 & 2012 & 167 & 37.180 & -73.514 \\
\hline 6 & 2313 & 167 & 37.161 & -73.533 \\
\hline 7 & 0059 & 168 & 37.153 & -73.532 \\
\hline 7 & 0650 & 168 & 37.143 & -73.532 \\
\hline 7 & 0838 & 168 & 37.136 & -73.531 \\
\hline 7 & 1311 & 168 & 37.108 & -73.493 \\
\hline 6 & 1450 & 168 & 37.099 & -73.489 \\
\hline 7 & 1815 & 168 & 37.050 & -73.528 \\
\hline 7 & 2001 & 168 & 37.039 & -73.544 \\
\hline 6 & 2250 & 168 & 37.025 & -73.593 \\
\hline 6 & 0036 & 169 & 37.026 & -73.607 \\
\hline 6 & 0639 & 169 & 37.053 & -73.673 \\
\hline 18 & 0826 & 169 & $3 ? .063$ & -73.685 \\
\hline 8 & 0958 & 169 & 37.075 & -73.681 \\
\hline 8 & 1247 & 159 & 37.071 & -73.674 \\
\hline 8 & 1432 & 169 & 37.059 & -73.670 \\
\hline 6 & 1803 & 169 & 37.049 & -73.701 \\
\hline 6 & 1950 & 169 & 37.051 & -73.707 \\
\hline 6 & 2226 & 169 & 37.055 & -73.734 \\
\hline 6 & 0147 & 170 & 37.082 & -73.741 \\
\hline 6 & 0626 & 170 & 37.099 & -73.722 \\
\hline 6 & 0947 & 170 & 37.098 & -73.697 \\
\hline 6 & 1224 & 170 & 37.092 & -73.682 \\
\hline 6 & 1408 & 170 & 37.083 & -73.670 \\
\hline 6 & 1751 & 170 & 37.069 & -73.661 \\
\hline 6 & 1938 & 170 & 37.051 & -73.647 \\
\hline 6 & 2343 & 170 & 37.006 & -73.652 \\
\hline 6 & 0129 & 171 & 36.983 & -73.660 \\
\hline 6 & 0614 & 171 & 36.965 & -73.715 \\
\hline 6 & 0940 & 171 & 36.965 & -73.740 \\
\hline 6 & 1201 & 171 & 36.968 & -73.755 \\
\hline 6 & 1347 & 171 & 36.968 & -73.749 \\
\hline 6 & 1740 & 171 & 36.056 & -73.761 \\
\hline 6 & 2319 & 171 & 36.928 & -73.811 \\
\hline 6 & 0106 & 172 & 36.928 & -73.832 \\
\hline 6 & 0743 & 172 & 36.974 & -73.902 \\
\hline 6 & 0927 & 172 & 36.998 & -73.909 \\
\hline 6 & 1137 & 172 & 37.022 & -73.897 \\
\hline
\end{tabular}


$-33-$

Table 3. (cont.)

$\begin{array}{llllll}21 & 6 & 1323 & 172 & 37.037 & -73.877 \\ 21 & 6 & 1728 & 172 & 37.061 & -73.816 \\ 21 & 6 & 2049 & 172 & 37.033 & -73.775 \\ 21 & 6 & 2257 & 172 & 37.021 & -73.765 \\ 22 & 6 & 0041 & 173 & 37.012 & -73.749 \\ 22 & 6 & 0731 & 173 & 36.986 & -73.705 \\ 22 & 6 & 0918 & 173 & 36.973 & -73.683 \\ 22 & 6 & 1113 & 173 & 36.955 & -73.664 \\ 22 & 6 & 1433 & 173 & 36.906 & -73.631 \\ 22 & 6 & 1716 & 173 & 36.864 & -73.634 \\ 22 & 6 & 1902 & 173 & 36.836 & -73.660 \\ 22 & 6 & 2041 & 173 & 36.820 & -73.667 \\ 22 & 6 & 2234 & 173 & 36.805 & -73.702 \\ 23 & 6 & 0719 & 174 & 36.781 & -73.806 \\ 23 & 6 & 0907 & 174 & 36.782 & -73.822 \\ 23 & 6 & 1410 & 174 & 36.775 & -73.866 \\ 23 & 6 & 1944 & 174 & 36.770 & -73.932 \\ 23 & 6 & 2030 & 174 & 36.778 & -73.958 \\ 23 & 6 & 2211 & 174 & 36.790 & -73.993 \\ 23 & 6 & 2355 & 174 & 36.812 & -74.017 \\ 24 & 6 & 0129 & 175 & 36.832 & -74.017 \\ 24 & 6 & 0133 & 175 & 36.833 & -74.021 \\ 24 & 6 & 0707 & 175 & 36.893 & -73.999 \\ 24 & 6 & 0854 & 175 & 36.904 & -73.986 \\ 24 & 6 & 1206 & 175 & 36.911 & -73.975 \\ 24 & 6 & 1353 & 175 & 36.913 & -73.967 \\ 24 & 6 & 1832 & 175 & 36.910 & -73.943 \\ 24 & 6 & 2018 & 175 & 36.910 & -73.933 \\ 24 & 6 & 2326 & 175 & 36.909 & -73.926 \\ 25 & 6 & 0112 & 176 & 36.908 & -73.909 \\ 25 & 6 & 0655 & 176 & 36.880 & -73.865 \\ 25 & 6 & 0843 & 176 & 36.869 & -73.849 \\ 25 & 6 & 1144 & 176 & 36.844 & -73.828 \\ 25 & 6 & 1329 & 176 & 36.824 & -73.809 \\ 25 & 6 & 1820 & 176 & 36.749 & -73.800 \\ 25 & 6 & 2007 & 176 & 36.723 & -73.817 \\ 25 & 6 & 2302 & 176 & 36.697 & -73.868 \\ 26 & 6 & 0048 & 177 & 36.1697 & -73.894 \\ 26 & 6 & 0644 & 177 & 36.721 & -73.971 \\ 26 & 6 & 0830 & 177 & 36.731 & -73.981 \\ 26 & 6 & 1120 & 177 & 36.747 & -73.996 \\ 26 & 6 & 1439 & 177 & 36.757 & -74.021 \\ 26 & 6 & 1808 & 177 & 36.761 & -74.041 \\ 26 & 6 & 1955 & 177 & 36.768 & -74.053 \\ 26 & 6 & 2240 & 177 & 36.796 & -74.103 \\ 27 & 6 & 0025 & 178 & 36.825 & -74.103 \\ 27 & 6 & 0631 & 178 & 36.921 & -74.086 \\ 27 & 6 & 0953 & 178 & 36.958 & -74.030 \\ 27 & 6 & 1236 & 178 & 36.960 & -73.972 \\ 27 & 6 & 1422 & 178 & 36.954 & -73.941 \\ 27 & 6 & 1757 & 178 & 36.933 & -73.906 \\ 27 & 6 & 1944 & 178 & 36.927 & -73.886\end{array}$


Table 4.

Positions of Argos drifter 03482 Endeavor 88

\begin{tabular}{cccccc} 
SHIP: & ENDEAVOR & CRUISE: & 88 & DATES: AUGUST & $5-25$. \\
\multicolumn{7}{c}{ DRIFTER: } & 34A2 \\
DATE & \multicolumn{7}{c}{ TIME } & YEAR DAY & LATITUDE & LONGITUDE \\
DAY MOS & GMT & & & DEG & DEG \\
& & & & & \\
14 & 8 & 2330 & 226 & 37.071 & -73.802 \\
15 & 8 & 0117 & 227 & 37.057 & -73.792 \\
15 & 8 & 0651 & 227 & 37.004 & -73.853 \\
15 & 8 & 0838 & 227 & 36.985 & -73.869 \\
15 & 8 & 1148 & 227 & 36.952 & -73.906 \\
15 & 8 & 1335 & 227 & 36.931 & -73.920 \\
15 & 8 & 1816 & 227 & 36.887 & -74.014 \\
15 & 8 & 2002 & 227 & 36.879 & -74.040 \\
15 & 8 & 2307 & 227 & 36.874 & -74.107 \\
16 & 8 & 0053 & 228 & 36.879 & -74.127 \\
16 & 8 & 0639 & 228 & 36.893 & -74.164 \\
16 & 8 & 0827 & 228 & 36.895 & -74.163 \\
16 & 8 & 0959 & 228 & 36.898 & -74.174 \\
16 & 8 & 1124 & 228 & 36.899 & -74.175 \\
16 & 8 & 1444 & 228 & 36.907 & -74.175 \\
16 & 8 & 1804 & 228 & 36.911 & -74.160 \\
16 & 8 & 1951 & 228 & 36.907 & -74.143 \\
16 & 8 & 2245 & 228 & 36.892 & -74.135 \\
17 & 8 & 0030 & 229 & 36.880 & -74.124 \\
17 & 8 & 0627 & 229 & 36.835 & -74.102 \\
17 & 8 & 0948 & 229 & 36.800 & -74.077 \\
17 & 8 & 1241 & 229 & 36.757 & -74.087 \\
17 & 8 & 1426 & 229 & 36.721 & -74.080 \\
17 & 8 & 1932 & 229 & 36.637 & -74.127 \\
17 & 8 & 2117 & 229 & 36.615 & -74.149 \\
17 & 8 & 2219 & 229 & 36.603 & -74.153 \\
18 & 8 & 0140 & 230 & 36.567 & -74.190 \\
18 & 8 & 0756 & 230 & 36.500 & -74.279 \\
18 & 8 & 0942 & 230 & 36.485 & -74.297 \\
18 & 8 & 1218 & 230 & 36.483 & -74.343 \\
18 & 8 & 1404 & 230 & 36.484 & -74.374 \\
18 & 8 & 1740 & 230 & 36.495 & -74.432 \\
18 & 8 & 2101 & 230 & 36.527 & -74.471 \\
18 & 8 & 2337 & 230 & 36.558 & -74.508 \\
19 & 8 & 0121 & 231 & 36.583 & -74.510 \\
19 & 8 & 0744 & 231 & 36.681 & -74.509 \\
19 & 8 & 0930 & 231 & 36.710 & -74.501 \\
19 & 8 & 1154 & 231 & 36.748 & -74.481 \\
19 & 8 & 1335 & 231 & 36.775 & -74.469
\end{tabular}


Table 5 .

Positions of Argos drifter 02535 Endeavor 88

\begin{tabular}{cccccc} 
SHIP: & ENOFAVOR & CRUISE: & 88 & DATES: AUGUST $5-25$, \\
\multicolumn{7}{c}{ DRIFTER: } & 2535 \\
DATE & \multicolumn{7}{c}{ TIME } & YEAR DAY & LATITUDE & LONGITUDE \\
DAY MOS & GMT & & DEG & DEG \\
14 & 8 & 2330 & 226 & 37.064 & -73.731 \\
15 & 8 & 0116 & 227 & 37.045 & -73.740 \\
15 & 8 & 0551 & 227 & 36.983 & -73.816 \\
15 & 8 & 0939 & 227 & 36.961 & -73.836 \\
15 & 8 & 1148 & 227 & 36.921 & -73.885 \\
15 & 8 & 1333 & 227 & 36.899 & -73.912 \\
15 & 8 & 1916 & 227 & 36.868 & -74.034 \\
15 & 8 & 2003 & 227 & 36.870 & -74.064 \\
15 & 8 & 2307 & 227 & 36.874 & -74.120 \\
16 & 8 & 0053 & 228 & 36.385 & -74.134 \\
16 & 8 & 0639 & 228 & 36.912 & -74.162 \\
16 & 8 & 0326 & 228 & 36.921 & -74.161 \\
16 & 8 & 0959 & 228 & 36.932 & -74.165 \\
16 & 8 & 1124 & 228 & 36.932 & -74.156 \\
16 & 8 & 1443 & 228 & 36.944 & -74.135 \\
16 & 8 & 1804 & 228 & 36.940 & -74.095 \\
16 & 8 & 1951 & 228 & 36.928 & -74.076 \\
16 & 8 & 2245 & 228 & 36.900 & -74.056 \\
17 & 8 & 0030 & 229 & 36.873 & -74.039 \\
17 & 8 & 0626 & 229 & 36.785 & -74.056 \\
17 & 8 & 0948 & 229 & 36.727 & -74.058 \\
17 & 8 & 1241 & 229 & 36.673 & -74.095 \\
17 & 8 & 1426 & 229 & 36.633 & -74.102 \\
17 & 8 & 1753 & 229 & 36.577 & -74.167 \\
17 & 8 & 1939 & 229 & 36.560 & -74.189 \\
18 & 8 & 0000 & 230 & 36.528 & -74.278 \\
18 & 8 & 0756 & 230 & 36.505 & -74.376 \\
18 & 8 & 0941 & 230 & 36.507 & -74.405 \\
18 & 8 & 1218 & 230 & 36.526 & -74.440 \\
18 & 8 & 1403 & 230 & 36.537 & -74.465 \\
18 & 8 & 1741 & 230 & 36.582 & -74.512 \\
18 & 8 & 2101 & 230 & 36.638 & -74.528 \\
18 & 8 & 2336 & 230 & 36.679 & -74.544 \\
19 & 8 & 0122 & 231 & 36.713 & -74.532 \\
19 & 8 & 0744 & 231 & 36.799 & -74.464 \\
19 & 8 & 0930 & 231 & 36.812 & -74.437 \\
19 & 8 & 1154 & 231 & 36.835 & -74.405 \\
19 & 8 & 1334 & 231 & 36.849 & -74.384 \\
19 & 8 & 1728 & 231 & 36.877 & -74.312
\end{tabular}


Table 6 .

Positions of Argos drifter 02535;

Second deployment Endeavor 88

SHIP: ENIFAVIR CRJISE: 88 DATES: AUGUST $5-25,1982$
DRIFTER: 2535



$\begin{array}{llllll}19 & 8 & 2049 & 231 & 36.655 & -74.322 \\ 19 & 8 & 2319 & 231 & 36.656 & -74.332 \\ 20 & 8 & 0053 & 232 & 36.658 & -74.335 \\ 20 & 8 & 0732 & 232 & 36.702 & -74.333 \\ 20 & 8 & 0917 & 232 & 36.713 & -74.317 \\ 20 & 8 & 1130 & 232 & 36.723 & -74.295 \\ 20 & 8 & 1317 & 232 & 36.721 & -74.267 \\ 20 & 8 & 1856 & 232 & 36.718 & -74.234 \\ 20 & 8 & 2042 & 232 & 36.719 & -74.215 \\ 20 & 8 & 2250 & 232 & 36.716 & -74.202 \\ 21 & 8 & 0036 & 233 & 36.707 & -74.178 \\ 21 & 8 & 0720 & 233 & 36.667 & -74.138 \\ 21 & 8 & 0907 & 233 & 36.654 & -74.122 \\ 21 & 8 & 1107 & 233 & 36.635 & -74.123 \\ 21 & 8 & 1432 & 233 & 36.597 & -74.122 \\ 21 & 8 & 1845 & 233 & 36.575 & -74.172 \\ 21 & 8 & 2031 & 233 & 36.579 & -74.189 \\ 21 & 8 & 2226 & 233 & 36.584 & -74.211 \\ 22 & 8 & 0146 & 234 & 36.603 & -74.234 \\ 22 & 8 & 0708 & 234 & 36.642 & -74.262 \\ 22 & 8 & 0856 & 234 & 36.653 & -74.266 \\ 22 & 8 & 1224 & 234 & 36.685 & -74.263 \\ 22 & 8 & 1409 & 234 & 36.700 & -74.258 \\ 22 & 8 & 1833 & 234 & 36.738 & -74.224 \\ 22 & 8 & 2019 & 234 & 36.750 & -74.194 \\ 22 & 8 & 2343 & 234 & 36.763 & -74.141 \\ 23 & 8 & 0128 & 235 & 36.765 & -74.108 \\ 23 & 8 & 0656 & 235 & 36.738 & -74.022 \\ 23 & 8 & 0843 & 235 & 36.727 & -74.000 \\ 23 & 8 & 1200 & 235 & 36.698 & -73.964 \\ 23 & 8 & 1340 & 235 & 36.681 & -73.942 \\ 23 & 8 & 1827 & 235 & 36.629 & -73.919 \\ 23 & 8 & 2001 & 235 & 36.618 & -73.916 \\ 23 & 8 & 2319 & 235 & 36.597 & -73.925 \\ 24 & 8 & 0105 & 236 & 36.589 & -73.928 \\ 24 & 8 & 0644 & 236 & 36.562 & -73.946 \\ 24 & 8 & 1000 & 236 & 36.562 & -73.961 \\ 24 & 8 & 1004 & 236 & 36.561 & -73.962 \\ 24 & 8 & 1137 & 236 & 36.547 & -73.980 \\ 24 & 8 & 1323 & 236 & 36.543 & -73.992 \\ 24 & 8 & 1909 & 236 & 36.534 & -74.063 \\ 24 & 8 & 1955 & 236 & 36.537 & -74.087 \\ 24 & 8 & 2256 & 236 & 36.544 & -74.155 \\ 25 & 8 & 0042 & 237 & 36.555 & -74.186 \\ 25 & 8 & 0632 & 237 & 36.503 & -74.262 \\ 25 & 8 & 0953 & 237 & 36.643 & -74.277 \\ 25 & 8 & 1112 & 237 & 36.648 & -74.278 \\ 25 & 8 & 1432 & 237 & 36.679 & -74.288 \\ 25 & 8 & 1758 & 237 & 36.722 & -74.278 \\ 25 & 8 & 1944 & 237 & 36.743 & -74.253 \\ 25 & 8 & 2232 & 237 & 36.765 & -74.220 \\ 26 & 8 & 0801 & 238 & 36.801 & -74.075 \\ 26 & 8 & 0946 & 238 & 36.801 & -74.042 \\ 26 & 8 & 1236 & 238 & 36.803 & -74.000 \\ 26 & 8 & 1410 & 238 & 36.804 & -73.977\end{array}$


Table 6. (cont.)

\begin{tabular}{|c|c|c|c|c|c|}
\hline 26 & 8 & 1745 & 238 & 36.791 & -73.908 \\
\hline 26 & 8 & 2106 & 238 & 36.752 & -73.859 \\
\hline 26 & 8 & 2349 & 238 & 36.732 & -73.829 \\
\hline 27 & 8 & 0134 & 239 & 36.713 & -73.822 \\
\hline 27 & 8 & 0749 & 239 & 36.652 & -73.837 \\
\hline 27 & 8 & 0935 & 239 & 36.632 & -73.837 \\
\hline 27 & 8 & 1207 & 239 & 36.615 & -73.870 \\
\hline 27 & 8 & 1352 & 239 & 36.597 & -73.890 \\
\hline 27 & 8 & 1732 & 239 & 36.570 & -73.959 \\
\hline 27 & 8 & 2054 & 239 & 36.557 & -74.029 \\
\hline 27 & 8 & 2325 & 239 & 36.537 & -74.094 \\
\hline 28 & 8 & 0111 & 240 & 36.532 & -74.139 \\
\hline 28 & 8 & 0737 & 240 & 36.556 & -74.301 \\
\hline 28 & 8 & 0923 & 240 & 36.569 & -74.325 \\
\hline 28 & 8 & 1143 & 240 & 36.586 & -74.355 \\
\hline 28 & 8 & 1330 & 240 & 36.604 & -74.372 \\
\hline 28 & 8 & 1902 & 240 & 36.661 & -74.437 \\
\hline 28 & 8 & 2047 & 240 & 36.690 & -74.441 \\
\hline 28 & 8 & 2302 & 240 & 36.728 & -74.445 \\
\hline 29 & 8 & 0048 & 241 & 36.752 & -74.426 \\
\hline 29 & 8 & 0725 & 241 & 36.806 & -74.319 \\
\hline 29 & 8 & 0910 & 241 & 36.806 & -74.288 \\
\hline 29 & 8 & 1120 & 241 & 36.802 & -74.257 \\
\hline 29 & 8 & 1438 & 241 & 36.800 & -74.213 \\
\hline 29 & 8 & 1849 & 241 & 36.766 & -74.144 \\
\hline 29 & 8 & 2032 & 241 & 36.745 & -74.120 \\
\hline 29 & 8 & 2239 & 241 & 36.729 & -74.093 \\
\hline 30 & 8 & 0024 & 242 & 36.703 & -74.075 \\
\hline 30 & 8 & 0713 & 242 & 36.585 & -74.075 \\
\hline 30 & 8 & 0901 & 242 & 36.565 & -74.096 \\
\hline 30 & 8 & 1237 & 242 & 36.532 & -74.171 \\
\hline 30 & 8 & 1421 & 242 & 36.512 & -74.207 \\
\hline 30 & 8 & 1837 & 242 & 36.487 & -74.326 \\
\hline 30 & 8 & 2024 & 242 & 36.489 & $-74 \cdot 361$ \\
\hline 30 & 8 & 2215 & 242 & 36.490 & -74.399 \\
\hline 31 & 8 & 0139 & 243 & .36 .511 & -74.468 \\
\hline 31 & 8 & 0701 & 243 & 36.562 & -74.524 \\
\hline 31 & 8 & 0849 & 243 & 36.582 & -74.542 \\
\hline 31 & 8 & 1212 & 243 & 36.634 & -74.555 \\
\hline 31 & 8 & 1358 & 243 & 36.664 & -74.563 \\
\hline 31 & 8 & 1826 & 243 & 36.738 & -74.513 \\
\hline 31 & 8 & 2011 & 243 & 36.759 & -74.479 \\
\hline 31 & 8 & 2331 & 243 & 36.790 & -74.441 \\
\hline 1 & 9 & 0116 & 244 & 36.803 & -74.409 \\
\hline 1 & 9 & 0649 & 244 & 36.820 & -74.299 \\
\hline 1 & 9 & 0837 & 244 & 36.814 & -74.259 \\
\hline 1 & 9 & 1149 & 244 & 36.785 & -74.210 \\
\hline 1 & 9 & 1336 & 244 & 36.762 & -74.180 \\
\hline 1 & 9 & 1820 & 244 & 36.701 & -74.147 \\
\hline 1 & 9 & 1954 & 244 & 36.682 & -74.137 \\
\hline 1 & 9 & 2307 & 244 & 36.648 & -74.140 \\
\hline 2 & 9 & 0054 & 245 & 36.631 & -74.142 \\
\hline 2 & 9 & 0637 & 245 & 36.584 & -74.198 \\
\hline 2 & 9 & 0958 & 245 & 36.557 & $-74 \cdot 245$ \\
\hline 2 & 9 & 1125 & 245 & 36.554 & -74.281 \\
\hline 2 & 9 & 1445 & 245 & 36.541 & -74.363 \\
\hline 2 & 9 & 1802 & 245 & 36.542 & -74.452 \\
\hline 2 & 9 & 1949 & 245 & 36.549 & -74.490 \\
\hline 2 & 9 & 2245 & 245 & 36.567 & -74.557 \\
\hline 3 & 9 & 0031 & 246 & 36.582 & -74.567 \\
\hline 3 & 9 & 0625 & 246 & 36.644 & -74.593 \\
\hline
\end{tabular}


Table 6. (cont.)

\begin{tabular}{|c|c|c|c|c|c|}
\hline 3 & 9 & 0946 & 246 & 36.679 & -74.593 \\
\hline 3 & 9 & 1242 & 246 & 36.712 & -74.579 \\
\hline 3 & 9 & 142.6 & 246 & 36.733 & -74.572 \\
\hline 3 & 9 & 1751 & 246 & 36.771 & -74.547 \\
\hline 3 & 9 & 1937 & 246 & 36.795 & -74.523 \\
\hline 3 & 9 & 2221 & 246 & 36.822 & -74.478 \\
\hline 4 & 9 & 0141 & 247 & 36.837 & -74.405 \\
\hline 4 & 9 & 0801 & 247 & 36.827 & -74.283 \\
\hline 4 & 9 & 0934 & 247 & 36.821 & -74.247 \\
\hline 4 & 9 & 1218 & 247 & 36.795 & -74.192 \\
\hline 4 & 9 & 1404 & 247 & 36.774 & -74.165 \\
\hline 4 & 9 & 1738 & 247 & 36.735 & -74.108 \\
\hline 4 & 9 & 2059 & 247 & 36.688 & -74.087 \\
\hline 4 & 9 & 2337 & 247 & 36.654 & -74.057 \\
\hline 5 & 9 & 0123 & 248 & 36.630 & -74.053 \\
\hline 5 & 9 & 0742 & 248 & 36.562 & -74.041 \\
\hline 5 & 9 & 0928 & 248 & 36.547 & -74.045 \\
\hline 5 & 9 & 1154 & 248 & 36.545 & -74.053 \\
\hline 5 & 9 & 1341 & 248 & 36.536 & -74.045 \\
\hline 5 & 9 & 1727 & 248 & 36.512 & -74.046 \\
\hline 5 & 9 & 2053 & 248 & 36.487 & -74.071 \\
\hline 5 & 9 & 2314 & 248 & 36.470 & -74.103 \\
\hline 6 & 9 & 0059 & 249 & 36.468 & $-74 \cdot 122$ \\
\hline 6 & 9 & 0730 & 249 & 36.447 & -74.254 \\
\hline 6 & 9 & 0917 & 249 & 36.446 & -74.293 \\
\hline 6 & 9 & 1131 & 249 & 36.449 & -74.355 \\
\hline 6 & 9 & 1450 & 249 & 36.451 & -74.442 \\
\hline 6 & 9 & 1451 & 249 & 36.449 & -74.442 \\
\hline 6 & 9 & 1854 & 249 & 36.468 & -74.537 \\
\hline 6 & 9 & 2041 & 249 & 36.475 & -74.568 \\
\hline 6 & 9 & 2251 & 249 & 36.475 & -74.598 \\
\hline 7 & 9 & 0037 & 250 & 36.477 & -74.616 \\
\hline 7 & 9 & 0718 & 250 & 36.478 & -74.667 \\
\hline 7 & 9 & 0905 & 250 & 36.470 & -74.671 \\
\hline 7 & 9 & 1248 & 250 & 36.454 & -74.700 \\
\hline 7 & 9 & 1433 & 250 & 36.438 & -74.711 \\
\hline 7 & 9 & 1842 & 250 & 3.6 .416 & -74.722 \\
\hline 7 & 9 & 2029 & 250 & 36.404 & -74.723 \\
\hline 7 & 9 & 2227 & 250 & 36.390 & -74.724 \\
\hline 8 & 9 & 0147 & 251 & 36.378 & -74.742 \\
\hline 8 & 9 & 0706 & 251 & 36.342 & -74.746 \\
\hline 8 & 9 & 0854 & 251 & 36.325 & -74.746 \\
\hline 8 & 9 & 1225 & 251 & 36.293 & -74.771 \\
\hline 8 & 9 & 1411 & 251 & 36.277 & -74.773 \\
\hline 8 & 9 & 1930 & 251 & 36.234 & -74.780 \\
\hline 8 & 9 & 2017 & 251 & 36.219 & -74.778 \\
\hline 8 & 9 & 2344 & 251 & 36.173 & -74.787 \\
\hline 9 & 9 & 0129 & 252 & 36.150 & -74.789 \\
\hline 9 & 9 & 0654 & 252 & 36.083 & -74.803 \\
\hline 9 & 9 & 0842 & 252 & 36.057 & -74.796 \\
\hline 9 & 9 & 1201 & 252 & 36.007 & -74.811 \\
\hline 9 & 9 & 1347 & 252 & 35.986 & -74.806 \\
\hline 9 & 9 & 1819 & 252 & 35.933 & -74.825 \\
\hline 9 & 9 & 2006 & 252 & 35.914 & -74.824 \\
\hline 9 & 9 & 2320 & 252 & 35.373 & -74.838 \\
\hline 10 & 9 & 0106 & 253 & 35.852 & -74.848 \\
\hline 10 & 9 & 0642 & 253 & 35.813 & -74.844 \\
\hline 10 & 9 & 1003 & 253 & 35.787 & -74.842 \\
\hline 10 & 9 & 1139 & 253 & 35.779 & -74.842 \\
\hline 10 & 9 & 1325 & 253 & 35.770 & -74.838 \\
\hline 10 & 9 & 1807 & 253 & 35.751 & -74.833 \\
\hline
\end{tabular}


Table 6. (cont.)

\begin{tabular}{|c|c|c|c|c|c|}
\hline 10 & 9 & 1953 & 253 & 35.747 & -74.823 \\
\hline 10 & 9 & 2257 & 253 & 35.742 & -74.817 \\
\hline 12 & 9 & 0040 & 254 & 35.734 & -74.806 \\
\hline 11 & 9 & 0630 & 254 & 35.738 & -74.786 \\
\hline 11 & 9 & 0951 & 254 & 35.728 & -74.762 \\
\hline 11 & 9 & 1113 & 254 & 35.721 & -74.749 \\
\hline 11 & 9 & 1434 & 254 & 35.720 & -74.726 \\
\hline 11 & 9 & 1756 & 254 & 35.720 & -74.715 \\
\hline 11 & 9 & 1942 & 254 & 35.716 & -74.706 \\
\hline 11 & 9 & 2234 & 254 & 35.711 & -74.715 \\
\hline 12 & 9 & 0152 & 255 & 35.706 & -74.721 \\
\hline 12 & 9 & 0759 & 255 & 35.705 & -74.743 \\
\hline 12 & 9 & 0945 & 255 & 35.702 & -74.755 \\
\hline 12 & 9 & 1231 & 255 & 35.697 & -74.766 \\
\hline 12 & 9 & 1416 & 255 & 35.698 & -74.773 \\
\hline 12 & 9 & 1744 & 255 & 35.704 & -74.797 \\
\hline 12 & 9 & 2104 & 255 & 35.707 & -74.793 \\
\hline 12 & 9 & 2349 & 255 & 35.707 & -74.805 \\
\hline 13 & 9 & 0133 & 256 & 35.717 & -74.801 \\
\hline 13 & 9 & 0746 & 256 & 35.741 & -74.806 \\
\hline 13 & 9 & 0933 & 256 & 35.746 & -74.807 \\
\hline 13 & 9 & 1208 & 256 & 35.752 & -74.812 \\
\hline 13 & 9 & 1354 & 256 & 35.755 & -74.811 \\
\hline 13 & 9 & 1731 & 256 & 35.768 & -74.825 \\
\hline 13 & 9 & 2056 & 256 & 35.778 & -74.829 \\
\hline 13 & 9 & 2326 & 256 & 35.779 & -74.836 \\
\hline 14 & 9 & 0110 & 257 & 35.783 & -74.841 \\
\hline 14 & 9 & 0735 & 257 & 35.802 & -74.858 \\
\hline 14 & 9 & 0922 & 257 & 35.809 & -74.862 \\
\hline 14 & 9 & 1144 & 257 & 35.818 & -74.864 \\
\hline 14 & 9 & 1859 & 257 & 35.835 & -74.875 \\
\hline 14 & 9 & 2045 & 257 & 35.835 & -74.875 \\
\hline 14 & 9 & 2303 & 257 & 35.836 & -74.880 \\
\hline 15 & 9 & 0048 & 258 & 35.836 & -74.879 \\
\hline 15 & 9 & 0.723 & 258 & 35.836 & -74.879 \\
\hline 15 & 9 & 0910 & 258 & 35.838 & -74.878 \\
\hline 15 & 9 & 1439 & 258 & 35.837 & -74.876 \\
\hline 15 & 9 & 1947 & 258 & 35.835 & -74.883 \\
\hline 15 & 9 & 2034 & 258 & 35.836 & -74.877 \\
\hline 15 & 9 & 2239 & 258 & 35.836 & -74.881 \\
\hline 16 & 9 & 0025 & 259 & 35.838 & -74.871 \\
\hline 16 & 9 & 0159 & 259 & 35.844 & -74.880 \\
\hline 16 & 9 & 0712 & 259 & 35.838 & -74.878 \\
\hline 16 & 9 & 0959 & 259 & 35.836 & -74.879 \\
\hline 16 & 9 & 1237 & 259 & 35.837 & -74.881 \\
\hline 16 & 9 & 1422 & 259 & 35.835 & -74.878 \\
\hline 16 & 9 & 1835 & 259 & 35.831 & -74.883 \\
\hline 16 & 9 & 2022 & 259 & 35.829 & -74.881 \\
\hline 16 & 9 & 2216 & 259 & 35.831 & -74.879 \\
\hline 17 & 9 & 0140 & 260 & 35.820 & -74.884 \\
\hline 17 & 9 & 0700 & 260 & 35.823 & -74.881 \\
\hline 17 & 9 & 0847 & 260 & 35.825 & -74.881 \\
\hline 17 & 9 & 1213 & 260 & 35.826 & -74.883 \\
\hline 17 & 9 & 1359 & 260 & 35.822 & -74.879 \\
\hline 17 & 9 & 1924 & 260 & 35.805 & -74.874 \\
\hline 17 & 9 & 2010 & 260 & 35.796 & -74.866 \\
\hline 17 & 9 & 2331 & 260 & 35.780 & -74.870 \\
\hline 18 & 9 & 0117 & 261 & 35.776 & -74.864 \\
\hline 18 & 9 & 0447 & 261 & 35.773 & -74.859 \\
\hline 18 & 9 & 0835 & 261 & 35.773 & -74.851 \\
\hline 18 & 9 & 1150 & 261 & 35.771 & -74.840 \\
\hline
\end{tabular}


Table 6. (cont.)

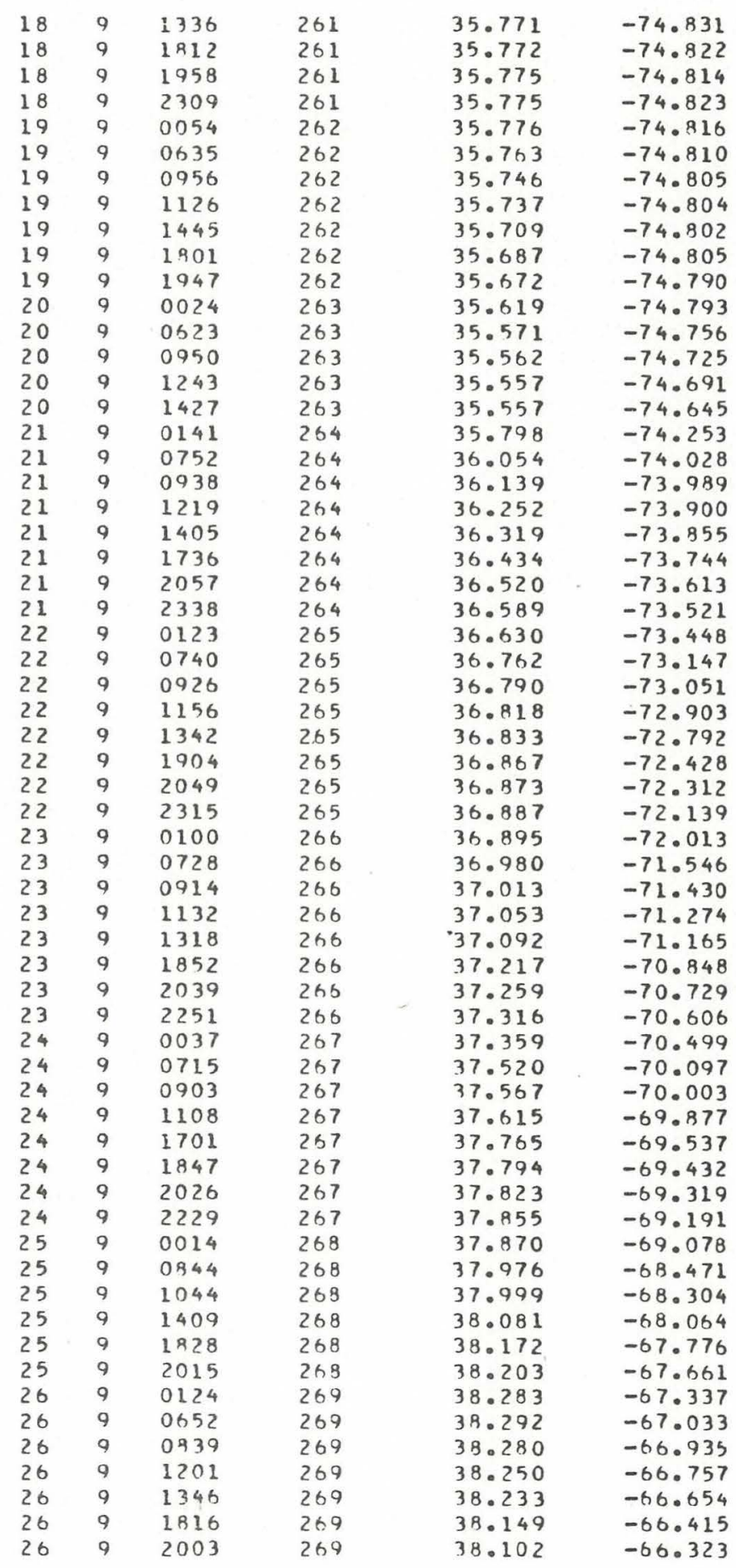


Table 6. (cont.)

\begin{tabular}{|c|c|c|c|c|c|}
\hline 26 & 9 & 2320 & 269 & 38.006 & -66.119 \\
\hline 27 & 9 & 0106 & 270 & 37.955 & -66.022 \\
\hline 27 & 9 & $0 \cap 38$ & 270 & 37.757 & -65.657 \\
\hline 27 & 9 & 0827 & 270 & 37.696 & -65.518 \\
\hline 27 & 9 & 1138 & 270 & 37.595 & -65.277 \\
\hline 27 & 9 & 1317 & 270 & 37.556 & $-65 \cdot 134$ \\
\hline 27 & 9 & 2257 & 270 & 37.469 & -64.275 \\
\hline 28 & 9 & 0042 & 271 & 37.475 & -64.127 \\
\hline 28 & 9 & 0308 & 271 & 37.619 & -63.553 \\
\hline 28 & 9 & 1114 & 271 & 37.761 & $-63 \cdot 367$ \\
\hline 28 & 9 & 1300 & 271 & 37.865 & -63.299 \\
\hline 28 & 9 & 1753 & 271 & 38.147 & -63.228 \\
\hline 28 & 9 & 1939 & 271 & 38.255 & -63.219 \\
\hline 28 & 9 & 2234 & 271 & 38.401 & $-63 \cdot 303$ \\
\hline 29 & 9 & 0019 & 272 & 38.494 & -63.344 \\
\hline 29 & 9 & 0615 & 272 & 38.723 & -63.637 \\
\hline 29 & 9 & 0803 & 272 & 38.762 & -63.748 \\
\hline 29 & 9 & 0940 & 272 & 38.779 & -63.858 \\
\hline 29 & 9 & 1049 & 272 & 38.789 & -63.929 \\
\hline 29 & 9 & 1409 & 272 & 38.778 & -64.130 \\
\hline 29 & 9 & 1742 & 272 & 38.766 & -64.456 \\
\hline 29 & 9 & 1928 & 272 & 38.757 & -64.579 \\
\hline 29 & 9 & 2210 & 272 & 38.734 & -64.785 \\
\hline 29 & 9 & 2356 & 272 & 38.731 & -64.898 \\
\hline 30 & 9 & 0604 & 273 & 38.720 & -65.297 \\
\hline 30 & 9 & 0924 & 273 & 38.721 & -65.509 \\
\hline 30 & 9 & 1207 & 273 & 38.766 & -65.680 \\
\hline 30 & 9 & 1352 & 273 & 38.903 & -65.781 \\
\hline 30 & 9 & 1729 & 273 & 38.898 & -65.965 \\
\hline 30 & 9 & 1916 & 273 & 38.966 & -66.023 \\
\hline 30 & 9 & 2147 & 273 & 39.057 & -66.129 \\
\hline 1 & 10 & 0106 & 274 & 39.173 & -66.212 \\
\hline 1 & 10 & 0732 & 274 & 39.449 & $-66 \cdot 325$ \\
\hline 1 & 10 & 0918 & 274 & 39.533 & $-66 \cdot 362$ \\
\hline 1 & 10 & 1143 & 274 & 39.642 & -66.337 \\
\hline 1 & 10 & 1329 & 274 & 39.725 & -66.320 \\
\hline 1 & 10 & 1717 & 274 & $39: 879$ & -66.237 \\
\hline 1 & 10 & 1903 & 274 & 39.947 & -66.170 \\
\hline 1 & 10 & 2124 & 274 & 40.027 & -66.074 \\
\hline 1 & 10 & 2310 & 274 & 40.090 & -66.008 \\
\hline 2 & 10 & 0049 & 275 & 40.140 & -65.926 \\
\hline 2 & 10 & 0719 & 275 & 40.303 & -65.547 \\
\hline 2 & 10 & 0906 & 275 & 40.326 & -65.436 \\
\hline 2 & 10 & 1119 & 275 & 40.349 & -65.315 \\
\hline 2 & 10 & 1305 & 275 & 40.365 & -65.202 \\
\hline 2 & 10 & 1705 & 275 & 40.378 & -64.958 \\
\hline 2 & 10 & 2026 & 275 & 40.340 & -64.741 \\
\hline 2 & 10 & 2240 & 275 & 40.328 & -64.588 \\
\hline 3 & 10 & 0026 & 276 & 40.294 & -64.487 \\
\hline 3 & 10 & 0708 & 276 & 40.113 & -64.159 \\
\hline 3 & 10 & 0953 & 276 & 40.057 & -64.072 \\
\hline 3 & 10 & 1055 & 276 & 39.992 & -63.998 \\
\hline 3 & 10 & 1243 & 276 & 39.925 & -63.928 \\
\hline 3 & 10 & 1419 & 276 & 39.866 & -63.884 \\
\hline 3 & 10 & 1654 & 276 & 39.773 & -63.820 \\
\hline 3 & 10 & 2014 & 276 & 39.667 & -63.765 \\
\hline 3 & 10 & 2215 & 276 & 39.623 & -63.716 \\
\hline 4 & 10 & $0 \cap 02$ & 277 & 39.586 & -53.686 \\
\hline 4 & 10 & 0655 & 277 & 39.501 & -63.599 \\
\hline 4 & 10 & 0843 & 277 & 39.492 & -63.575 \\
\hline 4 & 10 & 1031 & 277 & 39.485 & -63.562 \\
\hline
\end{tabular}


Table 6. (cont.)

$\begin{array}{llllll}4 & 10 & 1351 & 277 & 39.489 & -63.537 \\ 4 & 10 & 1821 & 277 & 39.501 & -63.519 \\ 4 & 10 & 2006 & 277 & 39.508 & -63.494 \\ 4 & 10 & 2153 & 277 & 39.525 & -63.499 \\ 4 & 10 & 2339 & 277 & 39.544 & -63.480 \\ 5 & 10 & 0644 & 278 & 39.606 & -63.482 \\ 5 & 10 & 0931 & 278 & 39.621 & -63.486 \\ 5 & 10 & 1149 & 278 & 39.652 & -63.500 \\ 5 & 10 & 1334 & 278 & 39.674 & -63.499 \\ 5 & 10 & 1310 & 278 & 39.696 & -63.516 \\ 5 & 10 & 1954 & 278 & 39.702 & -63.514 \\ 5 & 10 & 2309 & 278 & 39.708 & -63.557 \\ 6 & 10 & 0054 & 279 & 39.720 & -63.565 \\ 6 & 10 & 0631 & 279 & 39.722 & -63.577 \\ 6 & 10 & 0819 & 279 & 39.712 & -63.586 \\ 6 & 10 & 1125 & 279 & 39.705 & -63.620 \\ 6 & 10 & 1309 & 279 & 39.706 & -63.635 \\ 6 & 10 & 1758 & 279 & 39.700 & -63.655 \\ 6 & 10 & 1944 & 279 & 39.690 & -63.661 \\ 6 & 10 & 2245 & 279 & 39.676 & -63.690 \\ 7 & 10 & 0032 & 280 & 39.673 & -63.707 \\ 7 & 10 & 0619 & 280 & 39.656 & -63.713 \\ 7 & 10 & 0806 & 280 & 39.649 & -63.719 \\ 7 & 10 & 1102 & 280 & 39.630 & -63.747 \\ 7 & 10 & 1248 & 280 & 39.619 & -63.753 \\ 7 & 10 & 1745 & 280 & 39.595 & -63.786 \\ 7 & 10 & 1932 & 280 & 39.584 & -63.788 \\ 7 & 10 & 2222 & 280 & 39.561 & -63.808 \\ 8 & 10 & 0007 & 281 & 39.548 & -63.820 \\ 8 & 10 & 0608 & 281 & 39.515 & -63.860 \\ 8 & 10 & 0755 & 281 & 39.500 & -63.863 \\ 8 & 10 & 0928 & 281 & 39.489 & -63.866 \\ 8 & 10 & 1357 & 281 & 39.445 & -63.907 \\ 8 & 10 & 1733 & 281 & 39.437 & -63.925 \\ 8 & 10 & 1920 & 281 & 39.423 & -63.922 \\ 8 & 10 & 2159 & 281 & 39.404 & -63.923 \\ 8 & 10 & 2344 & 281 & 39.391 & -63.926 \\ 9 & 10 & 0555 & 282 & 39.355 & -63.966 \\ 9 & 10 & 0916 & 282 & 39.349 & -63.971 \\ 9 & 10 & 1155 & 282 & 39.333 & -63.976 \\ 9 & 10 & 1339 & 282 & 39.325 & -63.978 \\ 9 & 10 & 1723 & 282 & 39.313 & -63.998 \\ 9 & 10 & 1908 & 282 & 39.312 & -64.002 \\ 9 & 10 & 2136 & 282 & 39.304 & -64.008 \\ 10 & 10 & 0056 & 283 & 39.302 & -64.005 \\ 10 & 10 & 0724 & 283 & 39.272 & -64.044 \\ 10 & 10 & 0909 & 283 & 39.270 & -64.058 \\ 10 & 10 & 1131 & 283 & 39.271 & -64.089 \\ 10 & 10 & 1319 & 283 & 39.261 & -64.083\end{array}$


Table 7.

Positions of Argos drifter 03481 Endeavor 90

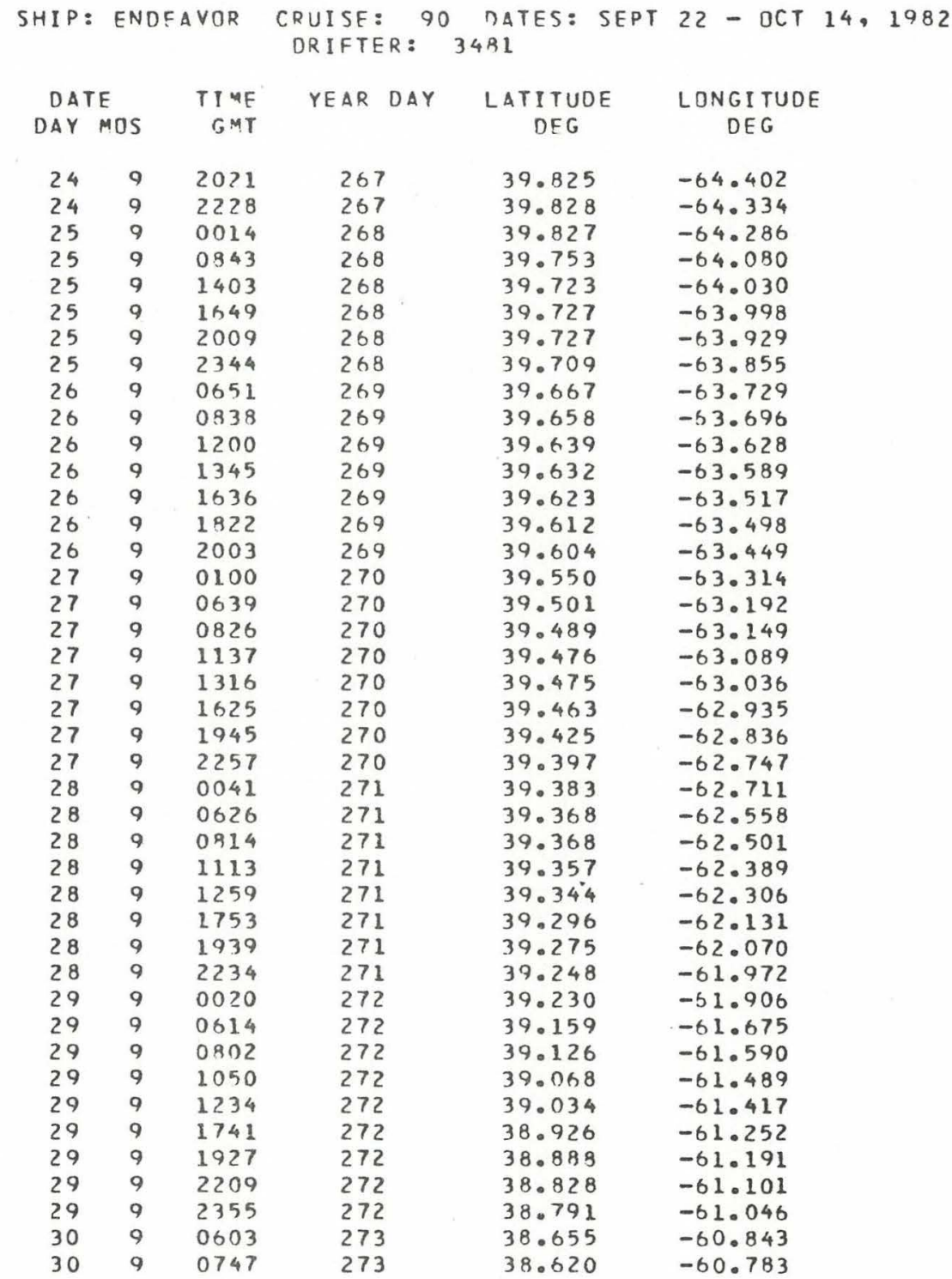


Table 8.

Positions of Argos drifter 03480 Endeavor 90

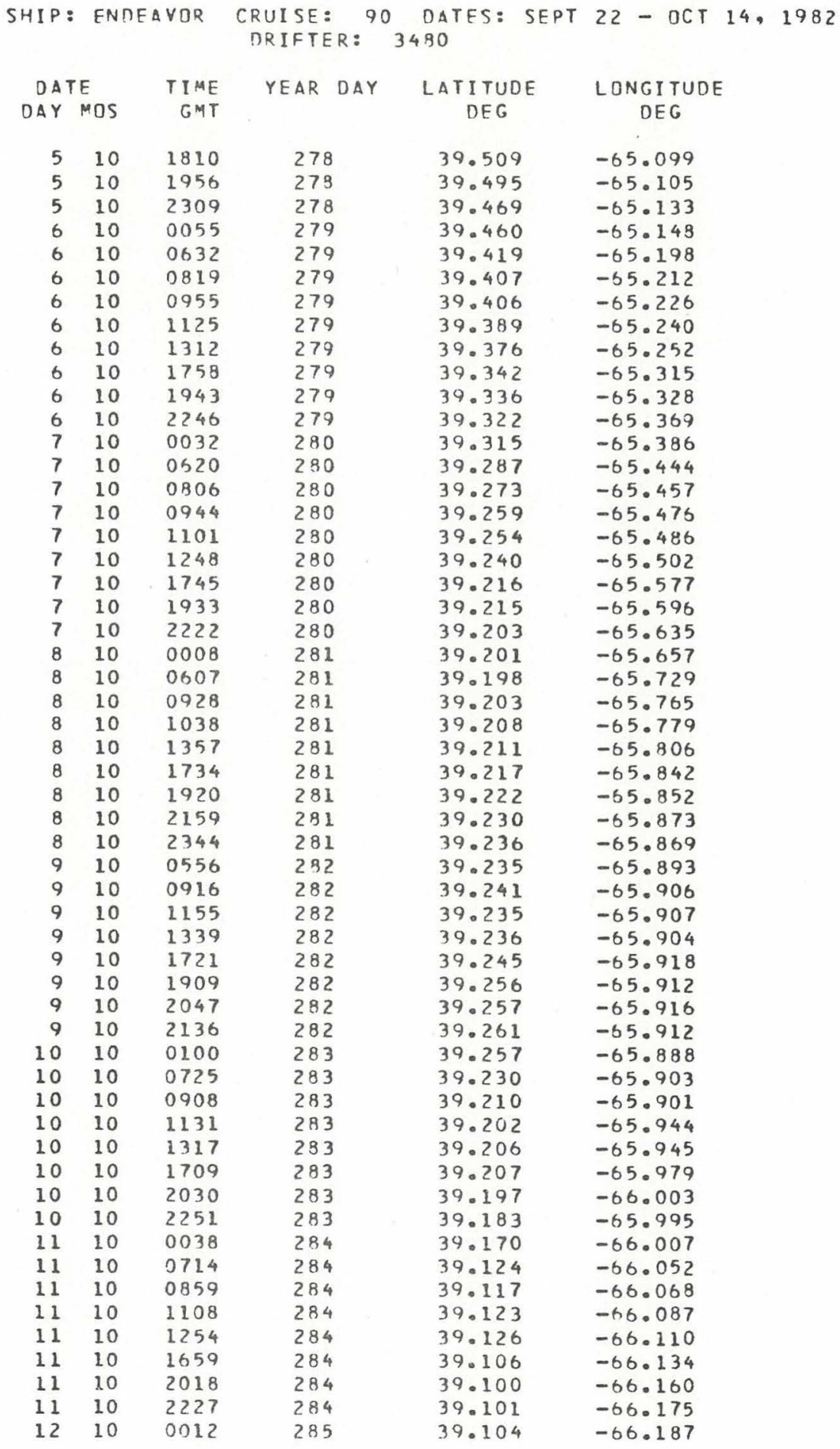


Table 8. (cont.)

$\begin{array}{llllll}12 & 10 & 0700 & 285 & 39.108 & -66.250 \\ 12 & 10 & 0847 & 285 & 39.111 & -66.271 \\ 12 & 10 & 1404 & 285 & 39.121 & -66.296 \\ 12 & 10 & 1647 & 285 & 39.145 & -66.309 \\ 12 & 10 & 1832 & 285 & 39.128 & -66.300 \\ 12 & 10 & 2011 & 285 & 39.126 & -66.289 \\ 12 & 10 & 2205 & 285 & 39.121 & -66.285 \\ 12 & 10 & 2350 & 285 & 39.114 & -66.292 \\ 13 & 10 & 0648 & 296 & 39.127 & -66.348 \\ 13 & 10 & 0.935 & 286 & 39.132 & -66.344 \\ 13 & 10 & 1201 & 286 & 39.136 & -66.340 \\ 13 & 10 & 1344 & 286 & 39.134 & -66.333 \\ 13 & 10 & 1813 & 286 & 39.138 & -66.330 \\ 13 & 10 & 2000 & 286 & 39.135 & -66.315 \\ 13 & 10 & 2320 & 286 & 39.129 & -66.322 \\ 14 & 10 & 0106 & 287 & 39.128 & -66.321 \\ 14 & 10 & 0636 & 287 & 39.140 & -66.316 \\ 14 & 10 & 0817 & 287 & 39.147 & -66.312 \\ 14 & 10 & 0957 & 287 & 39.155 & -66.299\end{array}$


Table 9.

Positions of Argos drifter 03481 Endeavor 90

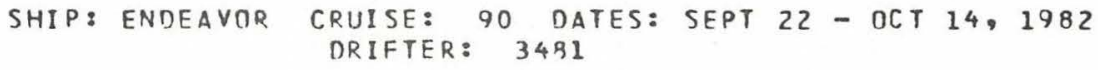

\begin{tabular}{|c|c|c|c|c|c|}
\hline & $T I$ M $E$ & YEAR DAY & LATITUDE & LONGITUD \\
\hline \multicolumn{2}{|c|}{$\begin{array}{l}\text { DATE } \\
\text { DAY MOS }\end{array}$} & GMT & & $D E G$ & $D E G$ \\
\hline 5 & 10 & 1149 & 278 & 39.123 & -64.830 \\
\hline 5 & 10 & 1334 & 278 & 39.106 & -64.876 \\
\hline 5 & 10 & 1809 & 278 & 39.056 & -65.006 \\
\hline 5 & 10 & 1956 & 278 & 39.041 & -65.056 \\
\hline 5 & 10 & 2309 & 278 & 39.009 & -65.170 \\
\hline 6 & 10 & 0055 & 279 & 39.000 & -65.224 \\
\hline 6 & 10 & 0631 & 279 & 38.973 & -65.407 \\
\hline 6 & 10 & 0820 & 279 & 38.968 & -65.466 \\
\hline 6 & 10 & 1126 & 279 & 38.972 & -65.553 \\
\hline 6 & 10 & 1312 & 279 & 38.967 & -65.602 \\
\hline 6 & 10 & 1758 & 279 & 38.955 & -65.745 \\
\hline 6 & 10 & 1944 & 279 & 38.955 & -65.793 \\
\hline 6 & 10 & 2244 & 279 & 38.964 & -65.900 \\
\hline 7 & 10 & 0032 & 280 & 38.980 & -65.943 \\
\hline 7 & 10 & 0620 & 280 & 39.024 & -66.076 \\
\hline 7 & 10 & 0808 & 280 & 39.040 & -66.106 \\
\hline 7 & 10 & 0944 & 280 & 39.051 & -66.133 \\
\hline 7 & 10 & 1102 & 280 & 39.056 & -66.153 \\
\hline 7 & 10 & 1248 & 280 & 39.064 & -66.178 \\
\hline 7 & 10 & 1745 & 280 & 39.099 & -66.279 \\
\hline 7 & 10 & 1932 & 280 & 39.121 & $-66 \cdot 301$ \\
\hline 7 & 10 & 2222 & 280 & 39.154 & $-66 \cdot 341$ \\
\hline 8 & 10 & 0006 & 281 & 39.177 & -66.347 \\
\hline 8 & 10 & 0607 & 281 & 39.247 & -66.375 \\
\hline 8 & 10 & 0928 & 281 & 39.279 & -66.387 \\
\hline 8 & 10 & 1038 & 281 & 39.289 & $-66 \cdot 386$ \\
\hline 8 & 10 & 1403 & 281 & 39.312 & -66.393 \\
\hline 8 & 10 & 1733 & 281 & 39.352 & -66.403 \\
\hline 8 & 10 & 1920 & 281 & 39.367 & -66.388 \\
\hline 8 & 10 & 2159 & 281 & 39.387 & -66.383 \\
\hline 9 & 10 & 0555 & 282 & 39.430 & -66.323 \\
\hline 9 & 10 & 0922 & 282 & 39.448 & -66.309 \\
\hline 9 & 10 & 1155 & 282 & 39.455 & -66.289 \\
\hline 9 & 10 & 1340 & 282 & 39.464 & -66.269 \\
\hline 9 & 10 & 1722 & 282 & 39.487 & -66.234 \\
\hline 9 & 10 & 1906 & 282 & 39.498 & -66.210 \\
\hline 9 & 10 & 2315 & 282 & 39.509 & -66.180 \\
\hline 10 & 10 & 0100 & 283 & 39.519 & -66.152 \\
\hline 10 & 10 & 0724 & 283 & 39.498 & -66.091 \\
\hline 10 & 10 & 0909 & 283 & 39.486 & -66.082 \\
\hline 10 & 10 & 1131 & 283 & 39.474 & -66.093 \\
\hline 10 & 10 & 1316 & 283 & 39.477 & -66.083 \\
\hline 10 & 10 & 1710 & 283 & 39.494 & -66.067 \\
\hline 10 & 10 & 2030 & 283 & 39.455 & -66.031 \\
\hline 10 & 10 & 2252 & 283 & 39.448 & -66.011 \\
\hline 11 & 10 & 0037 & 284 & 39.433 & -65.994 \\
\hline 11 & 10 & 0713 & 284 & 39.359 & -65.962 \\
\hline 11 & 10 & 0859 & 284 & 39.335 & -65.954 \\
\hline 11 & 10 & 1107 & 284 & 39.321 & -65.969 \\
\hline 11 & 10 & 1254 & 284 & 39.315 & -65.949 \\
\hline 11 & 10 & 1430 & 284 & 39.306 & -65.943 \\
\hline 11 & 10 & 1659 & 284 & 39.310 & -65.963 \\
\hline 11 & 10 & 2019 & 284 & 39.265 & -65.929 \\
\hline 11 & 10 & 2227 & 284 & 39.237 & -65.935 \\
\hline 12 & 10 & 0014 & 285 & 39.222 & -65.939 \\
\hline
\end{tabular}


Table 9. (cont.)




Table 10.

Positions of Argos drifter 03482 Endeavor 90

\begin{tabular}{|c|c|c|c|c|c|c|c|}
\hline \multicolumn{3}{|c|}{ SHIP: ENDEAVOR } & \multicolumn{2}{|c|}{$\begin{array}{l}\text { CRUISE: } \\
\text { DRIFTER: }\end{array}$} & $\begin{array}{l}\text { DATES: SEPT } \\
482\end{array}$ & 22 - OCT 14, & \multirow[t]{3}{*}{1982} \\
\hline \multicolumn{2}{|c|}{ DATE } & TIME & YEAR & DAY & LATITUDE & LONGITUDE & \\
\hline DAY & MOS & GMT & & & DEG & DEG & \\
\hline 5 & 10 & 2130 & 278 & & 39.333 & -65.227 & \\
\hline 5 & 10 & 2314 & 278 & & 39.316 & -65.274 & \\
\hline 6 & 10 & 0054 & 279 & & 39.309 & -65.300 & \\
\hline 6 & 10 & 0632 & 279 & & 39.299 & -65.421 & \\
\hline 6 & 10 & 0820 & 279 & & 39.300 & -65.457 & \\
\hline 6 & 10 & 1125 & 279 & & 39.298 & -65.508 & \\
\hline 6 & 10 & 1312 & 279 & & 39.292 & -65.536 & \\
\hline 6 & 10 & 1757 & 279 & & 39.291 & -65.627 & \\
\hline 6 & 10 & 1944 & 279 & & 39.299 & -65.652 & \\
\hline 6 & 10 & 2245 & 279 & & 39.298 & -65.701 & \\
\hline 7 & 10 & 0031 & 280 & & 39.302 & -65.731 & \\
\hline 7 & 10 & 0619 & 280 & & 39.346 & -65.806 & \\
\hline 7 & 10 & 0807 & 280 & & 39.357 & -65.811 & \\
\hline 7 & 10 & 0945 & 280 & & 39.362 & -65.823 & \\
\hline 7 & 10 & 1101 & 280 & & 39.364 & -65.828 & \\
\hline 7 & 10 & 1249 & 280 & & 39.367 & -65.836 & \\
\hline 7 & 10 & 1745 & 280 & & 39.398 & -65.875 & \\
\hline 7 & 10 & 1932 & 280 & & 39.407 & -65.870 & \\
\hline 7 & 10 & 2222 & 280 & & 39.417 & -65.885 & \\
\hline 8 & 10 & 0008 & 281 & & 39.432 & -65.883 & \\
\hline 8 & 10 & 0607 & 281 & & 39.481 & -65.855 & \\
\hline 8 & 10 & 0927 & 281 & & 39.499 & -65.833 & \\
\hline 8 & 10 & 1038 & 281 & & 39.504 & -55.820 & \\
\hline 8 & 10 & 1403 & 281 & & 39.514 & -65.790 & \\
\hline 8 & 10 & 1734 & 281 & & 39.525 & -65.760 & \\
\hline 8 & 10 & 1921 & 281 & & 39.530 & -65.733 & \\
\hline 8 & 10 & 2339 & 281 & & 39.552 & -65.668 & \\
\hline 9 & 10 & 0119 & 282 & & 39.551 & -65.638 & \\
\hline 9 & 10 & 0555 & 282 & & 39.521 & -65.536 & \\
\hline 9 & 10 & 0916 & 282 & & 39.507 & -65.490 & \\
\hline 9 & 10 & 1155 & 282 & & 39.483 & -65.450 & \\
\hline 9 & 10 & 1338 & 282 & & 39.469 & -65.414 & \\
\hline 9 & 10 & 1722 & 282 & & 39.433 & -65.372 & \\
\hline 9 & 10 & 1908 & 282 & & 39.414 & $-65 \cdot 344$ & \\
\hline 9 & 10 & 2135 & 282 & & 39.383 & -65.308 & \\
\hline 10 & 10 & 0100 & 283 & & 39.337 & -65.256 & \\
\hline 10 & 10 & 0723 & 283 & & 39.205 & -65.252 & \\
\hline 10 & 10 & 0910 & 283 & & 39.162 & -65.266 & \\
\hline 10 & 10 & 1132 & 283 & & 39.104 & -65.322 & \\
\hline 10 & 10 & 1317 & 283 & & 39.075 & -65.348 & \\
\hline 10 & 10 & 1710 & 283 & & 39.020 & -65.424 & \\
\hline 10 & 10 & 2031 & 283 & & 38.970 & -65.489 & \\
\hline 10 & 10 & 2251 & 283 & & 38.931 & -65.519 & \\
\hline 11 & 10 & 0037 & 284 & & 38.898 & -65.552 & \\
\hline 11 & 10 & 0713 & 284 & & 38.778 & -65.757 & \\
\hline 11 & 10 & 0859 & 284 & & 38.753 & -65.815 & \\
\hline 11 & 10 & 1108 & 284 & & 38.739 & -65.894 & \\
\hline 11 & 10 & 1254 & 284 & & 38.728 & -65.949 & \\
\hline 11 & 10 & 1657 & 284 & & 38.714 & -66.083 & \\
\hline 11 & 10 & 2019 & 284 & & 38.725 & -66.187 & \\
\hline 11 & 10 & 2227 & 284 & & 38.729 & -66.253 & \\
\hline 12 & 10 & 0014 & 285 & & 38.736 & -66.297 & \\
\hline 12 & 10 & 0701 & 285 & & 38.794 & -66.487 & \\
\hline 12 & 10 & 0847 & 285 & & 38.822 & -66.535 & \\
\hline 12 & 10 & 1044 & 285 & & 38.868 & -66.583 & \\
\hline
\end{tabular}


Table 10. (cont.)

\begin{tabular}{|c|c|c|c|c|c|}
\hline 12 & 10 & 1403 & 285 & 38.916 & -66.663 \\
\hline 12 & 10 & 1826 & 285 & 39.002 & -66.746 \\
\hline 12 & 10 & 2013 & 285 & 39.048 & -66.751 \\
\hline 12 & 10 & 2204 & 285 & 39.071 & -66.773 \\
\hline 12 & 10 & 2351 & 285 & 39.106 & -66.780 \\
\hline 13 & 10 & 0125 & 286 & 39.142 & -66.803 \\
\hline 13 & 10 & 0648 & 286 & 39.244 & -66.856 \\
\hline 13 & 10 & 0835 & 286 & 39.280 & -66.876 \\
\hline 13 & 10 & 1201 & 286 & 39.362 & -66.877 \\
\hline 13 & 10 & 1346 & 286 & 39.405 & -66.868 \\
\hline 13 & 10 & 1914 & 286 & 39.485 & -66.852 \\
\hline 13 & 10 & 2001 & 286 & 39.510 & -66.831 \\
\hline 13 & 10 & 2142 & 286 & 39.525 & -66.811 \\
\hline 14 & 10 & 0106 & 287 & 39.572 & -66.782 \\
\hline 14 & 10 & 0636 & 287 & 39.636 & -66.693 \\
\hline 14 & 10 & 0817 & 287 & 39.651 & -66.662 \\
\hline 14 & 10 & 1137 & 287 & 39.675 & -66.582 \\
\hline 14 & 10 & 1322 & 287 & 39.678 & -66.535 \\
\hline 14 & 10 & 1802 & 287 & 39.678 & -66.428 \\
\hline 14 & 10 & 1949 & 287 & 39.672 & -66.368 \\
\hline 14 & 10 & 2258 & 287. & 39.639 & -66.261 \\
\hline 15 & 10 & 0043 & 288 & 39.608 & -66.204 \\
\hline 15 & 10 & 0625 & 288 & 39.481 & -66.058 \\
\hline 15 & 10 & 0312 & 288 & 39.445 & -66.017 \\
\hline 15 & 10 & 0947 & 288 & 39.421 & -65.971 \\
\hline 15 & 10 & 1113 & 288 & 39.383 & -65.964 \\
\hline 15 & 10 & 1.301 & 288 & 39.347 & -65.911 \\
\hline 15 & 10 & 1748 & 288 & 39.238 & -65.792 \\
\hline 15 & 10 & 1935 & 288 & 39.190 & -65.744 \\
\hline 15 & 10 & 2234 & 288 & 39.096 & -65.679 \\
\hline 16 & 10 & 0020 & 289 & 39.033 & -65.667 \\
\hline 16 & 10 & 0612 & 289 & 38.848 & -65.626 \\
\hline 16 & 10 & 0759 & 289 & 38.795 & -65.603 \\
\hline 16 & 10 & 0933 & 289 & 38.754 & -65.590 \\
\hline 16 & 10 & 1050 & 289 & 38.711 & -65.584 \\
\hline 16 & 10 & 1409 & 289 & 38.593 & -65.549 \\
\hline 16 & 10 & 1737 & 289 & 38.476 & -65.530 \\
\hline 16 & 10 & 1924 & 289 & 38.408 & -65.527 \\
\hline 16 & 10 & 2210 & 289 & 38.304 & -65.520 \\
\hline 16 & 10 & 2355 & 289 & 38.238 & -65.527 \\
\hline 17 & 10 & 0601 & 290 & 38.001 & -65.555 \\
\hline 17 & 10 & 0922 & 290 & 37.878 & -65.545 \\
\hline 17 & 10 & 1207 & 290 & 37.772 & -65.565 \\
\hline 17 & 10 & 1352 & 290 & 37.690 & -65.547 \\
\hline 17 & 10 & 1726 & 290 & 37.539 & -65.537 \\
\hline 17 & 10 & 1912 & 290 & 37.457 & -65.544 \\
\hline 17 & 10 & 2147 & 290 & 37.348 & -65.555 \\
\hline 18 & 10 & 0105 & 291 & 37.215 & -65.594 \\
\hline 18 & 10 & 0730 & 291 & 37.021 & -65.569 \\
\hline 18 & 10 & 0915 & 291 & 36.958 & -65.534 \\
\hline 18 & 10 & 1144 & 291 & 36.873 & -65.515 \\
\hline 18 & 10 & 1328 & 291 & 36.813 & -65.492 \\
\hline 18 & 10 & 1714 & 291 & 36.712 & -65.473 \\
\hline 18 & 10 & 1901 & 291 & 36.672 & -65.457 \\
\hline 18 & 10 & 2035 & 291 & 36.635 & -65.471 \\
\hline 18 & 10 & 2303 & 291 & 36.602 & -65.441 \\
\hline 19 & 10 & 0048 & 292 & 36.569 & -65.421 \\
\hline 19 & 10 & 0718 & 292 & 36.455 & -65.328 \\
\hline 19 & 10 & 0903 & 292 & 36.425 & -65.306 \\
\hline 19 & 10 & 1120 & 292 & 36.386 & -65.289 \\
\hline 19 & 10 & 1306 & 292 & 36.356 & -65.274 \\
\hline 19 & 10 & 1701 & 292 & 36.317 & -65.249 \\
\hline 19 & 10 & 2023 & 292 & 36.285 & -65.223 \\
\hline 19 & 10 & 2239 & 292 & 36.257 & -65.196 \\
\hline
\end{tabular}


Table 11.

Positions of Argos drifter 03480 USNS Bartlett 40-b

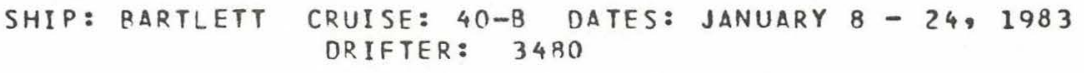

$\begin{array}{llllll}11 & 1 & 0710 & 11 & 40.521 & -65.839 \\ 11 & 1 & 0855 & 11 & 40.517 & -65.839 \\ 11 & 1 & 1137 & 11 & 40.515 & -65.845 \\ 11 & 1 & 1322 & 11 & 40.503 & -65.852 \\ 11 & 1 & 1656 & 11 & 40.491 & -65.869 \\ 11 & 1 & 2023 & 11 & 40.509 & -65.868 \\ 11 & 1 & 2258 & 11 & 40.514 & -65.856 \\ 12 & 1 & 0043 & 12 & 40.501 & -65.840 \\ 12 & 1 & 0658 & 12 & 40.432 & -65.854 \\ 12 & 1 & 0843 & 12 & 40.420 & -65.861 \\ 12 & 1 & 1113 & 12 & 40.413 & -65.879 \\ 12 & 1 & 1300 & 12 & 40.404 & -65.882 \\ 12 & 1 & 1436 & 12 & 40.403 & -65.895 \\ 12 & 1 & 1644 & 12 & 40.379 & -65.886 \\ 12 & 1 & 1830 & 12 & 40.367 & -65.902 \\ 12 & 1 & 2010 & 12 & 40.354 & -65.915 \\ 12 & 1 & 2234 & 12 & 40.326 & -65.955 \\ 13 & 1 & 0020 & 13 & 40.324 & -65.972 \\ 13 & 1 & 0645 & 13 & 40.302 & -66.064 \\ 13 & 1 & 0834 & 13 & 40.290 & -66.086 \\ 13 & 1 & 1009 & 13 & 40.282 & -66.136 \\ 13 & 1 & 1049 & 13 & 40.290 & -66.119 \\ 13 & 1 & 1409 & 13 & 40.298 & -66.154 \\ 13 & 1 & 1812 & 13 & 40.310 & -66.191 \\ 13 & 1 & 1959 & 13 & 40.319 & -66.196 \\ 13 & 1 & 2211 & 13 & 40.334 & -66.225\end{array}$


Table 12.

A Gregorian to year day calendar conversion

\begin{tabular}{|c|c|c|c|c|c|c|c|c|c|c|c|c|c|}
\hline Ocy & Jan & Feb & Mor & $\hat{A p r}$ & $\therefore$ Aoy & June & July & Aug & Sep & $\mathrm{Cel}$ & Nov & Dee & Doy \\
\hline 1 & 001 & 032 & 060 & 091 & 121 & 152 & 182 & 213 & 244 & 274 & 305 & 335 & 1 \\
\hline 2 & 002 & 033 & 061 & 092 & 122 & 153 & 183 & 214 & 245 & 275 & 305 & 336 & 2 \\
\hline 3 & 003 & 034 & 062 & 093 & 123 & 154 & 184 & 215 & 246 & 276 & 307 & 337 & 3 \\
\hline 4 & 004 & 035 & 063 & 094 & 124 & 155 & 185 & 216 & 247 & 277 & 308 & 338 & 4 \\
\hline 5 & 005 & 036 & 004 & 095 & 125 & 156 & 186 & 217 & 248 & 278 & 309 & 339 & 5 \\
\hline 6 & 006 & 037 & 065 & 096 & 126 & 157 & 187 & 218 & 249 & 279 & 310 & 340 & 6 \\
\hline 7 & 007 & 038 & 066 & 097 & 127 & 158 & 188 & 219 & 250 & 280 & 311 & 341 & 7 \\
\hline 8 & 008 & 039 & 067 & 098 & 128 & 159 & 189 & 220 & 251 & 281 & 312 & 312 & 8 \\
\hline 9 & 009 & 040 & $\mathrm{CoB}$ & 099 & 129 & 160 & 190 & 221 & 252 & 232 & 313 & 343 & 9 \\
\hline 10 & 010 & 0.41 & 069 & 100 & 130 & 161 & 191 & 222 & 253 & 283 & 314 & 344 & 10 \\
\hline 11 & 011 & 042 & 070 & 101 & 131 & 162 & 192 & 223 & 254 & 284 & 315 & 345 & 11 \\
\hline 12 & 012 & 043 & 071 & 102 & 132 & 163 & 193 & 224 & 255 & 285 & 316 & $3 \div 6$ & 12 \\
\hline 13 & 013 & 044 & 072 & 103 & 133 & 164 & 194 & 225 & 256 & 286 & 317 & 347 & 13 \\
\hline 14 & 014 & 045 & 073 & 104 & 1 & 16 & 195 & 226 & 257 & 287 & 318 & 348 & 14 \\
\hline 15 & 015 & 0.45 & 074 & 105 & 135 & 166 & 196 & 227 & 258 & 288 & 319 & $3 \div 9$ & 15 \\
\hline 16 & 016 & 047 & 075 & 106 & 136 & 167 & 197 & 228 & 259 & 289 & 320 & 350 & 16 \\
\hline 17 & 017 & 048 & 076 & 107 & 137 & 168 & 198 & 229 & 260 & 290 & 321 & 351 & 17 \\
\hline 18 & 018 & 049 & 077 & 108 & 138 & 169 & 199 & 230 & 261 & 291 & 322 & 352 & 18 \\
\hline 19 & 019 & 050 & 078 & 109 & 139 & 17 & 200 & 231 & 262 & 292 & 323 & 53 & 19 \\
\hline 20 & 020 & 051 & 079 & 110 & 140 & 171 & 201 & 232 & 263 & 293 & 324 & 354 & 20 \\
\hline 21 & 021 & 052 & 080 & 111 & 141 & 172 & 202 & 233 & 264 & 291 & 325 & 355 & 21 \\
\hline 22 & 022 & 053 & 081 & 112 & 142 & 173 & 203 & 234 & 265 & 295 & 326 & 356 & 22 \\
\hline 23 & 023 & 054 & 082 & 113 & 143 & $17 d$ & 204 & 235 & 260 & 296 & 327 & 357 & 23 \\
\hline 24 & 024 & 055 & 083 & 114 & 144 & 175 & 205 & 236 & 267 & 297 & 328 & 358 & 24 \\
\hline 25 & 025 & 056 & 084 & 115 & 145 & 176 & 206 & 237 & 268 & 298 & 329 & 359 & 25 \\
\hline 26 & 026 & 057 & 085 & 116 & 146 & 177 & 207 & 238 & 269 & 299 & 330 & 360 & 26 \\
\hline 27 & 027 & 058 & 086 & 117 & 147 & 178 & 208 & 239 & 270 & 300 & 331 & 361 & 27 \\
\hline 28 & 028 & 059 & 087 & 118 & 148 & 179 & 209 & 240 & 271 & 301 & 332 & 362 & 28 \\
\hline 29 & 029 & & 088 & 119 & 149 & 180 & 210 & 241 & 272 & 302 & 333 & 363 & 29 \\
\hline 30 & 030 & & 089 & 120 & 150 & 181 & 211 & 242 & 273 & 303 & 334 & 364 & 30 \\
\hline 31 & 031 & & 090 & & 151 & & 212 & 243 & & 304 & & 365 & 31 \\
\hline
\end{tabular}




\section{DOCUMENT LIBRARY}

August 3, 1984

\section{DISTRIBUTION LIST FOR TECHNICAL REPORT EXCHANGE}

Institute of Marine Sciences Library

University of Alaska

O'Neill Building

905 Koyukuk Ave. North

Fairbanks, AK

Attn: Stella Sanchez-Wade

Documents Section

Scripps Institution of Oceanography

Library, Mail Code C-075C

La Jolla, CA 92093

Hancock Library of Biology \& Oceanography

Alan Hancock Laboratory

University of Southern California

Los Angeles, CA 90007

Gifts \& Exchanges

Library

Bedford Institute of Oceanography

P.O. Box 1006

Dartmouth, NS, B2Y 4A2, CANADA

Office of the International

Ice Patrol

c/o Coast Guard R\&D Center

Avery Point

Groton, CT 06340

\section{Library}

Physical Oceanographic Laboratory

Nova University

8000 N. Ocean Drive

Dania, FL 33304

NOAA/EDIS Miami Library Center

4301 Rickenbacker Causeway

Miami, FL 33149

\section{Library}

Skidaway Institute of Oceanography

P.O. Box 13687

Savannah, GA 31406

Institute of Geophysics

University of Hawaii

Library Room 252

2525 Correa Road

Honolulu, HI 96822
Library

Chesapeake Bay Institute

4800 Atwell Road

Shady Side, MD 20876

MIT Libraries

Serial Journal Room 14E-210

Cambridge, MA 02139

Director, Ralph M. Parsons Laboratory

Room 48-311

MIT

Cambridge, MA 02139

Marine Resources Information Center

Bldg. E38-320

MIT

Cambridge, MA 02139

Library

Lamont-Doherty Geological Observatory

Colombia University

Palisades, NY 10964

Library

Serials Department

Oregon State University

Corvallis, OR 97331

Pell Marine Science Library

University of Rhode Island

Narragansett Bay Campus

Narragansett, RI 02882

Working Collection

Texas A\&M University

Dept. of Oceanography

College Station, TX 77843

Library

Virginia Institute of Marine Science

Gloucester Point, VA 23062

Fisheries-Oceanography Library

151 Oceanography Teaching Bldg.

University of Washington

Seattle, WA 98195

Library

R.S.M.A.S.

University of Miami

4600 Rickenbacker Causeway

Miami, FL 33149 


\begin{tabular}{|c|c|c|c|}
\hline $\begin{array}{l}\text { REPORT DOCUMENTATION } \\
\text { PAGE }\end{array}$ & $\begin{array}{l}\text { 1. REPORT NO. } \\
\text { WHOI-84-27 }\end{array}$ & 2. & 3. Rocipient's Accession No. \\
\hline \multirow{2}{*}{\multicolumn{2}{|c|}{$\begin{array}{l}\text { 4. Title and Subtitle } \\
\text { Drifter Studies in Warm Core Rings }\end{array}$}} & & \begin{tabular}{|l|} 
5. Report Date \\
April 1984 \\
\end{tabular} \\
\hline & & & 6. \\
\hline \multicolumn{3}{|c|}{$\begin{array}{l}\text { 7. Author(s) } \\
\text { Cynthia T. Tynan and Stanford B. Hooker }\end{array}$} & $\begin{array}{l}\text { 8. Performing Organization Rept. No. } \\
\text { WHOI-84-27 }\end{array}$ \\
\hline \multirow{2}{*}{\multicolumn{2}{|c|}{$\begin{array}{l}\text { 9. Performing Organization Name and Address } \\
\text { Woods Hole Oceanographic Institution } \\
\text { Woods Hole, Massachusetts } 02543\end{array}$}} & & 10. Project/Task/Work Unit No. \\
\hline & & & $\begin{array}{l}\text { 11. Contract(C) or Grant(G) No. } \\
\text { (C) OCE } 80-16983 \\
\text { (G) }\end{array}$ \\
\hline \multirow{2}{*}{\multicolumn{2}{|c|}{$\begin{array}{l}\text { 12. Sponsoring Organization Name and Address } \\
\text { National Science Foundation }\end{array}$}} & & $\begin{array}{l}\text { 13. Type of Report \& Period Covered } \\
\text { Technical }\end{array}$ \\
\hline & & & 14. \\
\hline
\end{tabular}

15. Supplementary Notes

This report should be cited as: Woods Hole Oceanog. Inst. Tech Rept. WHOI-84-27.

16. Abstract (Limit: 200 words)

The results of multiple deployments of surface drifters in warm core rings of the Gulf Stream are presented. Four satellite drifters (tracked by the Argos system) were deployed on nine separate occasions and two LORAN-C drifters (operated by the University of Miami) were deployed three times. Drifter studies were conducted during four cruises aboard the R/V Endeavor in 1982 in conjunction with the Warm Core Rings Experiment and one cruise of the USNS Bartlett in January 1983 which was sponsored by the Office of Naval Research. Translational velocities and periods of rotation are provided for two rings: $82 \mathrm{~B}$ and $82 \mathrm{H}$.

17. Document Analysis a. Descriptors

1. Drifters

2. Gulf Stream

3. Warm core rings

b. Identifiers/Open-Ended Terms

c. COSATI Field/Group

18. Availability Statemen:

Approved for publication; distribution unlimited.

19. Security Class (This Report)

UNCLASSIFIED

20. Security Class (This Page)
21. No. of Pages 51

22. Price 